\title{
Nominal Rigidities and Asset Pricing
}

\author{
Michael Weber*
}

November 21, 2013

\begin{abstract}
This paper examines the asset-pricing implications of nominal rigidities. I find that firms that adjust their product prices infrequently earn a cross-sectional return premium of more than $4 \%$ per year. Merging confidential product price data at the firm level with stock returns, I document that the premium for sticky-price firms is a robust feature of the data and is not driven by other firm and industry characteristics. The consumption-wealth ratio is a strong predictor of the return differential in the time series, and differential exposure to systematic risk fully explains the premium in the cross section. The sticky-price portfolio has a conditional market $\beta$ of 1.3 , which is 0.4 higher than the $\beta$ of the flexible-price portfolio. The frequency of price adjustment is therefore a strong determinant of the cross section of stock returns. To rationalize these facts, I develop a multi-sector production-based asset-pricing model with sectors differing in their frequency of price adjustment.
\end{abstract}

\section{JEL classification: E12, E44, E52, G12}

\section{Keywords: Sticky Prices; Stock Returns; Monetary Policy}

\footnotetext{
*Haas School of Business, University of California at Berkeley, Berkeley, CA, USA. e-Mail: michael_ weber@haas.berkeley.edu. Cell: (510) 725-9033. Homepage: faculty.haas.berkeley.edu/michael I would like to thank the members of my dissertation committee for their constant support and invaluable guidance throughout: Yuriy Gorodnichenko, Martin Lettau, Richard Sloan, and Richard Stanton. I would also like to thank Javed Ahmed, Patrick Augustin, Bradyn Breon-Drish, Oli Coibion, Francesco D'Acunto, Ben Farber, Jon Faust, Willie Fuchs, Nicolae Gârleanu, Pierre-Olivier Gourinchas, Chad Jones, Amir Kermani, Ralph Koijen, Samuli Knüpfer, Ryan Liu, Dmitry Livdan, Dong Lou, Ben Malin, Gustavo Manso, Matteo Maggiori, Tim McQuade, Adair Morse, Maurice Obstfeld, Christine Parlour, Demian Pouzo, Valerie Ramey, Andrés Rodríguez-Clare, David Romer, Andrew Rose, Philipp Schnabl, Martin Schneider, Lumi Stevens, Victoria Vanasco, Annette Vissing-Jørgensen, Johan Walden, and seminar participants at Berkeley (Econ, Haas Finance) and the Best Finance Ph.D. award poster session at Olin for valuable comments. Financial support from IBER at UC Berkeley, the White Foundation, and the Minder Cheng Fellowship are gratefully acknowledged. This research was conducted with restricted access to the Bureau of Labor Statistics (BLS) data. The views expressed here are those of the author and do not necessarily reflect the views of the BLS. I thank the project coordinator at the BLS, Ryan Ogden, for help with the data, and Emi Nakamura and Jón Steinsson for making their data available. I also thank Kenneth Kuttner for sharing his data on monthly Federal Funds rate surprises. Any remaining errors are my own.
} 


\section{Introduction}

The cover price of the Wall Street Journal was constant during the Roaring Twenties, the Great Depression, and the Second World War despite large swings in economic conditions. ${ }^{1}$ Although this example is certainly extreme, rigid product prices are pervasive at the micro level. ${ }^{2}$ Nominal rigidities play a central role in macroeconomics in explaining businesscycle dynamics of aggregate real variables and are key ingredients of dynamic models at policy institutions such as the Federal Reserve. ${ }^{3}$ Most importantly, price rigidities are the cornerstone of many economic models that rationalize the effects of purely nominal shocks on the real side of the economy. ${ }^{4}$

In this paper, I study whether infrequent product-price changes at the firm level are a source of macroeconomic risk, which is priced in the cross section of stock returns. I document for the first time that firms with sticky prices earn a return premium of more than $4 \%$ per year compared to firms with flexible prices. The premium for sticky-price firms is in the order of magnitude of the size and value premia that are the most studied cross-sectional return-premia in finance. The premium is robust to controlling for standard return predictors at the firm and industry level and is fully explained by differences in exposure to systematic risk. Hence sticky-price firms are risky and command a return premium. To rationalize these findings, I develop a multi-sector production-based assetpricing model in which sectors differ in the degree of price stickiness.

Price rigidities are therefore not only central to explaining the business-cycle dynamics of aggregate real variables such as gross domestic output or investment, they also predict the cross section of stock returns. A firm's exposure to systematic risk is a function of many parameters and factors. The frequency of product price adjustment is a simple variable at the firm level that can account for a considerable part of the variation in firms' exposure to systematic risk.

Specifically, I measure price stickiness as the average frequency of product price

\footnotetext{
${ }^{1}$ See Knotek II (2008) and Figure 1.

${ }^{2}$ Prices at the good level remain unchanged for roughly six months. See, for example, Bils and Klenow (2004) and Nakamura and Steinsson (2008).

${ }^{3}$ See Christiano, Eichenbaum, and Evans (2005) and Smets and Wouters (2007). Galí (2009) starts his textbook with "That framework has emerged as the workhorse for the analysis of monetary policy and its implications for inflation, economic fluctuations, and welfare. It constitutes the backbone of the new generation of medium-scale models under development at [...] the Federal Reserve Board, [...] and many other central banks."

${ }^{4}$ Kehoe and Midrigan (2012) express this notion in the first line of their paper: "A widely held view in macroeconomics is that monetary policy can be effective primarily because aggregate prices are sticky."
} 
adjustment at the firm level. I construct this metric using the confidential microdata underlying the Producer Price Index (PPI) at the Bureau of Labor Statistics (BLS), and merge it with financial data from the Center for Research in Security Prices (CRSP) and Compustat. I show that portfolios of firms sorted on the frequency of price adjustment generate a return spread of $4.4 \%$ per year between sticky- and flexible-price firms. Portfolio returns monotonically decrease in the degree of price flexibility.

The return premium for sticky-price firms is a robust feature of the data. In panel regressions, moving from a firm with rigid prices to a firm with flexible prices leads to an annual return differential of $6 \%$. Adding year fixed effects and additional covariates at the firm and industry level has no impact on this finding. A specification with all controls implies an annual return premium of $4 \%$. The premium for sticky-price firms is also not driven by non-linear relationships between firm characteristics and returns. Controlling non-parametrically for return predictors in double sorts, I show that the premium for sticky-price firms is still highly statistically significant and similar in magnitude to the value premium. Exploiting only variation in the frequency of price adjustment within industry, I document that my previous findings are not due to unobserved industry-level characteristics.

I then investigate the properties of the return premium. First, I test whether differential exposure to systematic risk can explain the portfolio returns. The Capital Asset Pricing Model (CAPM) cannot explain the level of portfolio returns, but it can explain the cross-sectional dispersion: the sticky-price portfolio has a conditional $\beta$ with the market excess return of 1.29 . $\beta$ s decrease monotonically in price flexibility, resulting in a $\beta$ differential of 0.37 between the sticky- and flexible-price portfolios. Second, I examine the time-series characteristics of the return premium. I construct a zero-cost portfolio, which invests in stocks with low frequency of price adjustment, and funds this investment by selling short flexible price firms (L-H in the following). I check if the premium varies systematically over the business cycle and if it can be predicted in long-horizon regressions. I find that the premium for sticky-price firms is higher in recessions and times of low market returns. The Lettau and Ludvigson (2001) proxy for the consumption-wealth ratio (cay) can explain up to $60 \%$ of the time-series variation.

To organize these facts in a coherent setting, I develop a multi-sector productionbased asset-pricing model. Households derive utility from a composite consumption good and leisure. The production side is organized in different sectors. Firms are 
monopolistically competitive and set prices as a markup over a weighted average of future marginal costs. The only heterogeneity across sectors is a different degree of price stickiness motivated by the empirical findings of Nakamura and Steinsson (2008). The basic structure of my model is similar to Carvalho (2006). ${ }^{5}$ Mine differs in several ways. I add external habit formation in consumption and wage stickiness to get a reasonable equity premium. ${ }^{6}$ I also allow for different elasticities of substitution in consumption varieties within and across sectors as they play a distinct role for cross-sectional return premia.

I calibrate the model using standard parameters to the empirical distribution of price stickiness from Nakamura and Steinsson (2008). In portfolio sorts, the model generates a spread in returns of $2.4 \%$ per year between firms with low and high frequencies of price adjustment. In regressions of annual stock returns on the monthly frequency of price adjustment, coefficients are quantitatively in line with my empirical results. The premium for firms with low frequency of price adjustment varies substantially over the business cycle and is highly predictable by habit-adjusted consumption. The model-implied equity premium is in the range of historical estimates.

Low relative payoffs in times of high marginal utility are central for cross-sectional return premia. I show that three margins determine the return difference between stickyand flexible-price firms: a quantity margin, a price margin, and an inefficiency margin associated with price dispersion. The quantity margin captures the sensitivity of sectoral output to price differentials across sectors, which is the price margin, while the inefficiency margin reflects lost output due to dispersion in prices. To gain intuition for the three margins, consider the effects of a contractionary monetary policy shock. Aggregate output decreases after the shock, as does the aggregate wage rate, whereas marginal utility goes up. Firms want to lower their product prices to accommodate the lower demand and marginal costs. Sticky-price firms, however, are stuck at their currently too high prices. Consumers therefore substitute away to firms in the flexible-price sector because of their lower relative prices. In terms of revenues, firms in the sticky-price sector gain along the price margin but lose along the quantity margin. In addition, the dispersion in prices is higher in the sticky-price sector, resulting in lower output and dividends. The three

\footnotetext{
${ }^{5}$ Carvalho (2006) studies the persistent effects of nominal shocks on aggregate real outcomes in the presence of differences in the frequency of price adjustment.

${ }^{6}$ I use habit-formation preferences instead of Epstein and Zin (1989) and Weil (1989) recursive utility, because they are more standard in macro models (see, e.g., Boldrin, Christiano, and Fisher (2001), Christiano et al. (2005), and Smets and Wouters (2007)).
} 
margins combined result in lower dividends for sticky-price firms in times of high marginal utility compared to firms with flexible prices.

The key condition for a sizeable return premium for sticky-price firms is a sufficiently large elasticity of substitution between consumption varieties within sectors. I show that the disadvantage of sticky-price firms along the quantity margin and the advantage along the price margin decrease in the within-sector elasticity, whereas the disadvantage along the price-dispersion margin increases in this elasticity. The effects on the price and inefficiency margins are quantitatively more important than the impact on the quantity margin, and the return differential increases in the within-sector elasticity.

Wage stickiness increases the level of the equity premium in the model. Dividends equal output minus wages. In an economy with frictionless labor markets, wages equal the marginal product of labor and are therefore perfectly correlated with output. A drop in demand leads to a drop in output, but at the same time, it also decreases the wage bill. Hence dividends exhibit too little variation in any reasonable calibration. The Calvo (1983)-style wage-setting friction de-couples the average wage paid by a firm from the marginal product of labor. In times of low output and high marginal utility, the wage rate of some labor types cannot be adjusted downward. Firms therefore have to incur higher wages in bad times. This mechanism makes claims on dividends riskier than claims on production, and boosts the level of the equity premium. ${ }^{7}$

The paper is organized as follows. The next subsection reviews the related literature. Section II describes how I measure the frequency of price adjustment at the firm level and my data sources. In Section III, I first document cross-sectional patterns at the portfolio level. I then move on to panel regressions and double sorts before I perform CAPM and long-horizon regressions again at the portfolio level. Section IV develops and calibrates a multi-sector New Keynesian production-based asset-pricing model to organize the empirical facts in a unified framework. Section V concludes and lays out directions for future research.

\section{A. Related Literature}

The paper is related to a large literature in macroeconomics documenting stylized facts about the pricing behavior of firms, and the asset-pricing literature on production-based asset pricing, the equity premium, and the relationship between firm characteristics

\footnotetext{
${ }^{7}$ Wage stickiness is equal across sectors and therefore primarily affects the level of the equity premium.
} 
and cross-sectional return-premia. I contribute to the macroeconomics literature by documenting that differences in the frequency of price adjustment are associated with differences in expected returns. Price stickiness therefore has real costs for firms; it increases the cost of capital, and firms might forgo profitable investment projects. I contribute to the finance literature by documenting that the frequency of price adjustment is a strong determinant of exposure to systematic risk and is a priced risk factor in the cross section of stock returns.

\section{A.1 Macroeconomics}

This paper builds on the literature on price stickiness. Using data from retail catalogs, Kashyap (1995) shows that nominal prices are fixed for more than one year. Zbaracki, Ritson, Levy, Dutta, and Bergen (2004) document in detail for a large U.S. manufacturer the costs associated with changing prices, such as data collection, managerial costs, physical costs, or negotiation costs. The total cost of changing nominal prices can be as high as $1.22 \%$ of total revenue and $20.03 \%$ of the company's net profit margin. Bils and Klenow (2004) and Nakamura and Steinsson (2008) use the microdata underlying the Consumer Price Index (CPI) at the BLS to show that prices are fixed for roughly six months and that substantial heterogeneity is present in price stickiness across industries. Goldberg and Hellerstein (2011) confirm these findings for producer prices. ${ }^{8}$ More recent research exploits information in asset prices to answer macro questions linking the micro data of the BLS with financial data from CRSP and Compustat. Gorodnichenko and Weber (2013) use the micro data underlying the PPI to test alternative theories of price stickiness in the micro data. Performing high-frequency-event studies around the press releases of the Federal Open Market Committee, they document costs associated with nominal price adjustments. Their findings support the New Keynesian interpretation of price stickiness. Gilchrist, Schoenle, Sim, and Zakrajsek (2013) investigate inflation dynamics during recessions at the industry level and for firms close to default.

\footnotetext{
${ }^{8}$ Other recent contributions to this literature are Golosov and Lucas Jr. (2007), Klenow and Willis (2007), Klenow and Kryvtsov (2008), Knotek II (2008), Eichenbaum, Jaimovich, and Rebelo (2011), Midrigan (2011), Anderson, Jaimovich, and Simester (2012), Kehoe and Midrigan (2012), Bhattarai and Schoenle (2012), Eichenbaum, Jaimovich, Rebelo, and Smith (2013), Kaplan and Menzio (2013), and Vavra (2013). Klenow and Malin (2010) and Nakamura and Steinsson (2013) provide excellent reviews of the recent literature on price rigidity using micro price data.
} 


\section{A.2 Finance}

This paper is also related to the literature on production-based asset pricing and the equity premium. The external-habit formation model of Campbell and Cochrane (1999) and the long-run risk model of Bansal and Yaron (2004) as well as rare disasters in the tradition of Rietz (1988), Barro (2006) and Gabaix (2012) have been successful in generating empirically plausible levels of the equity premium in endowment economies. The equity-premium puzzle of Mehra and Prescott (1985), however, reappears if one puts these frameworks in a frictionless production economy: Lettau and Uhlig (2000) and Boldrin, Christiano, and Fisher (2001) show that habits alone cannot generate an equity premium, because agents can use the production technology and labor supply to smooth consumption. Jermann (1998), Zhang (2005), and others introduce investment-adjustment costs to address this problem and generate a sizeable equity premium. Kaltenbrunner and Lochstoer (2010) and Croce (2012) document that long-run risk can generate an equity premium in a production economy. More recent research focuses on the potential of wage and price rigidities to explain aggregate stock market patterns. Uhlig (2007) shows that external habits and real-wage stickiness generate an equity premium. Favilukis and Lin (2013) develop a production-based asset-pricing model with sticky wages and employment-adjustment costs. Li and Palomino (2012) develop a multi-sector production-based asset-pricing model with sticky prices and wages. Both papers have Epstein and Zin (1989) and Weil (1989) recursive preferences and are able to generate empirically reasonable levels of the equity risk premium in calibrations. ${ }^{9}$ I contribute to this literature by theoretically showing the impact of heterogeneity in price stickiness on cross-sectional return premia. To the best of my knowledge, this paper is the first to test for the effects of nominal rigidities on stock returns at the firm level.

In addition, I contribute to the literature linking firm characteristics to stock returns in the cross section. Fama and French (1992) offer a concise treatment of the size effect of Banz (1981), the value premium of Rosenberg, Reid, and Lanstein (1985), and other cross-sectional relationships in a unified setting. Berk, Green, and Naik (1999), Carlson, Fisher, and Giammarino (2004), Gomes, Kogan, and Zhang (2003), and Kogan (2004) document that these premia naturally arise from firms' optimal production and investment behavior. Hou and Robinson (2006), Bustamante and Donangelo (2012), and Donangelo

\footnotetext{
${ }^{9}$ Kuehn, Petrosky-Nadeau, and Zhang (2012) incorporate search and matching frictions in a production-based asset-pricing model and show that this friction endogenously generates consumption disasters.
} 
(2013) relate industry concentration, product market competition, and labor mobility across industries to expected returns in the cross section. Van Binsbergen (2012) studies the impact of good-specific habit formation and finds that cross-sectional variation in the demand for goods leads to differences in expected returns. ${ }^{10}$

I add to this literature by documenting that different pricing technologies in product markets lead to different exposure to systematic risk. A difference in average conditional $\beta$ s of almost 0.40 explains the return spread between sticky- and flexible-price firms.

\section{Data}

This section describes both my measure of the frequency of product price adjustment at the firm level, and the financial data I use.

\section{A. Measuring Price Stickiness}

A key ingredient of my analysis is a measure of price stickiness at the firm level. I use the confidential microdata underlying the PPI at the BLS to calculate the frequency of price adjustment at the firm level. The PPI measures changes in selling prices from the perspective of producers, and tracks prices of all goods-producing industries such as mining, manufacturing, gas and electricity, as well as the service sector. ${ }^{11}$

The BLS applies a three-stage procedure to determine the individual sample goods. In the first stage, the BLS compiles a list of all firms filing with the Unemployment Insurance system to construct the universe of all establishments in the United States. In the second and third stages, the BLS probabilistically selects sample establishments and goods based on the total value of shipments or on the number of employees. The BLS collects prices from about 25,000 establishments for approximately 100,000 individual items on a monthly basis. The BLS defines PPI prices as "net revenue accruing to a specified producing establishment from a specified kind of buyer for a specified product shipped under specified transaction terms on a specified day of the month." Prices are collected via a survey that is emailed or faxed to participating establishments. ${ }^{12}$ Individual

\footnotetext{
${ }^{10}$ See also Gomes, Kogan, and Yogo (2009), Novy-Marx (2011), Gârleanu, Kogan, and Panageas (2012), Kogan and Papanikolaou (2012), Ahern (2012), and Jones and Tuzel (2012), among many others.

${ }^{11}$ The BLS started sampling prices for the service sector in 2005. The PPI covers about $75 \%$ of the service sector output. My sample of micro price data ranges from 1982 to 2011. The data until 1998 are equivalent to the data used in Nakamura and Steinsson (2008).

${ }^{12}$ Appendix E. contains a historical sample survey.
} 
establishments remain in the sample for an average of seven years until a new sample is selected to account for changes in the industry structure.

I calculate the frequency of price adjustment at the good level, $S A$, as the ratio of price changes to the number of sample months. For example, if an observed price path is $\$ 4$ for two months and then $\$ 5$ for another three months, one price change occurs during five months and the frequency is $1 / 5 .^{13} \mathrm{I}$ calculate both equally weighted frequencies, $U$, and frequencies weighted by values of shipments associated with items/establishments, $W$.

I then first aggregate goods-based frequencies to the establishment level via internal identifiers of the BLS. To perform the firm-level aggregation, I check whether establishments with the same or similar names are part of the same company. In addition, I use publicly available data to search for names of subsidiaries and name changes due to, for example, mergers, acquisitions, or restructuring occurring during the sample period for all firms in the dataset. The appendix discusses in more detail how the aggregations are performed.

Table 1 reports mean frequencies, standard deviations, and the number of firm-month observations for the frequency of price adjustment, both for the total sample and at the industry level. ${ }^{14}$ I focus on the unweighted frequency of price adjustment, $S A U$, because results are similar across the two measures. The overall mean monthly frequency of price adjustment is $14.86 \%$, which implies an average duration, $-1 / \ln (1-S A U)$, of 6.22 months. Substantial heterogeneity is present in the frequency across sectors, ranging from as low as $8.13 \%$ for the service sector (duration of one year) to $22.75 \%$ for agriculture (duration of 3.88 months). Finally, the high standard deviations highlight large heterogeneity in measured price stickiness across firms even within industries.

Different degrees of price stickiness of similar firms operating in the same industry can arise due to differences in the costs of negotiating with customers and suppliers, in the physical costs of changing prices, or in the managerial costs such as information gathering,

\footnotetext{
${ }^{13}$ When calculating the frequency of price adjustment, I exclude price changes due to sales, using the filter of Nakamura and Steinsson (2008). Including sales does not affect my results because sales are rare in producer prices (see Nakamura and Steinsson (2008)). My baseline measure treats missing price values as interrupting price spells. The appendix contains results for alternative measures of the frequency of price adjustment; results are quantitatively and statistically similar.

${ }^{14}$ The coarse definition of industry is due to confidentiality reasons and partially explains the substantial variation of the measures of price stickiness within industry.
} 
decision making, and communication. ${ }^{15}$

\section{B. Financial Data}

Stock return, shares outstanding and volume data are from the CRSP Monthly Stock file. I focus on firms that have been part of the S\&P500 between 1994 and 2009 because of the availability of the PPI data and to keep the manual merging between the two datasets manageable. ${ }^{16}$ Size of year $\mathrm{t}$ is the natural logarithm of the total market capitalization at the firm level as of December t-1. $\beta$ (Beta) is the regression coefficient in rolling time-series regressions of monthly excess returns on a constant and the excess returns of the CRSP value-weighted index over a 60 -month period. Turnover is the ratio of volume to shares outstanding (in percent). Spread is the monthly average of the daily bid-ask spreads from the CRSP Daily Stock file.

I obtain balance-sheet data from the Standard and Poor's Compustat database. I define book equity (BE) as total stockholders' equity plus deferred taxes and investment tax credit (if available) minus the book value of preferred stock. Based on availability, I use the redemption value, liquidation value, or par value (in that order) for the book value of preferred stock. I prefer the shareholders' equity number as reported by Compustat. If not available, I calculate shareholders' equity as the sum of common and preferred equity. If none of the two are available, I define shareholders' equity as the difference between total assets and total liabilities. The book-to-market (BM) ratio of year $\mathrm{t}$ is then the book equity for the fiscal year ending in calendar year t-1 over the market equity as of December t-1. Leverage (Lev) is the ratio of total long-term debt and debt in current liabilities over the sum of the numerator and shareholders' equity. Cash flow (CF) is the sum of income before extraordinary items and depreciation and amortization over total assets. I calculate the price-to-cost margin (PCM) as net sales minus cost of goods sold over net sales and HHI as the Herfindahl-Hirschman index of sales at the Fama \& French 48 industry level at an annual frequency. ${ }^{17}$

Table 2 summarizes time-series averages of annual means and standard deviations of

\footnotetext{
${ }^{15}$ These differences might arise because of, for example, differences in customer and supplier structure, heterogeneous organizational structure, or varying operational efficiencies and management philosophies (see Zbaracki et al. (2004)).

${ }^{16}$ I have 956 unique firms in my sample due to changes in the index composition during my sample period, out of which I was able to merge 760 with the BLS pricing data.

${ }^{17} \mathrm{I}$ winsorize all variables at the $2.5 \%$ level to minimize the effect of extreme observations and outliers. Results are similar if I perform my analysis on unwinsorized data (see appendix).
} 
the return predictors in Panel A as well as contemporaneous correlations in Panel B. I have on average more than 500 firms per year. My sample consists of large major U.S. companies with a mean size of more than $\$ 3$ billion and a $\beta$ of slightly above 1 . In Panel B, we see that firms with more flexible prices have higher book-to-market ratios and leverage, but also lower $\beta_{\mathrm{s}}$ and price-to-cost margins. The positive correlation with leverage might indicate that price flexibility in product markets increases the debt capacity of firms via reduced default costs. The higher $\beta$ for sticky-price firms suggests higher riskiness. The positive correlation with the price-to-cost margin highlights the importance of disentangling the frequency of price adjustment from other covariates. Firms with low frequencies of price adjustment might have market power and therefore be unresponsive to changes in costs or demand instead of facing costs of changing nominal prices.

\section{Empirical Results}

I first sort stocks into five portfolios based on their frequency of price adjustment to test if differences in price stickiness are associated with differences in returns. I then run a series of panel regressions to disentangle a return premium for price stickiness from other cross-sectional-return predictors. I also perform conditional double sorts on characteristics and the frequency of price adjustment to allow for non-linearities between returns and characteristics. Lastly, I test whether the CAPM can explain the crosssectional-return difference. I investigate the conditional association between portfolio returns and monetary policy shocks, and I look at business-cycle variation in the return premium.

\section{A. Portfolio Level}

I sort stocks into five portfolios based on the frequency of price adjustment, SAU. The frequency of price adjustment is by construction monotonically increasing from as low as 0.01 for portfolio 1 to 0.35 for the flexible price portfolio (see Table 16 in the appendix for firm characteristics at the portfolio level). I measure annual returns from July of year t to June of year $\mathrm{t}+1$, and I weight returns equally within each portfolio. ${ }^{18}$

Panel A of Table 3 reports average annual returns for various sample periods. The

\footnotetext{
${ }^{18}$ Because the frequency of price adjustment at the firm level shows little variation over time, I do not rebalance portfolios but only sort once at the beginning of the sample period.
} 
sorting generates a spread in returns between the sticky- and flexible-price portfolios of $2.7 \%-6.7 \%$ per year. This premium is statistically significant and economically large. Mean returns decrease monotonically in the degree of price flexibility. The return premium is larger after the Volcker disinflation, with a non-binding zero lower bound on interest rates and before the start of the Great Recession. In the rest of the paper, I focus on a period from July of 1982 to June of 2007. The micro data I use to construct the frequency of price adjustment start in 1982. I limit the analysis to 2007 because doing so allows me to circumvent the concerns associated with a binding zero lower bound on nominal interest rates and the effects of the Great Recession. Results for the full sample are similar (see appendix).

In Panel B, I report returns adjusted for firm characteristics associated with stock returns in the cross section. Following Daniel, Grinblatt, Titman, and Wermers (1997), I sequentially sort all common stocks of the CRSP universe into one of 125 benchmark portfolios based on size, industry-adjusted book-to-market, and momentum. I then assign each stock in my sample to a benchmark portfolio based on its size, book-to-market ratio, and previous 12-month return. I calculate benchmark-adjusted returns by subtracting the assigned portfolio returns from the individual stock returns. An adjusted return of zero implies the total stock return is explained by the stock's characteristics.

Standard stock characteristics cannot explain the return premium for sticky-price firms. We see in Panel B that differences in the frequency of price adjustment still lead to a differential return of $2.1 \%-5.6 \%$ even after controlling for these characteristics. Portfolio returns are monotonic in the portfolio number.

For comparison, Panel C reports the average annual returns for the CRSP valueweighted and equally weighted indexes and the size and value premia of Fama and French (1993). The average annual return for the CRSP indexes is $15 \%$ and $16.8 \%$, respectively, during my benchmark sample period. The size premium is less than $1 \%$ and statistically insignificant, whereas the value premium is $5.6 \%$. The premium for sticky-price firms is therefore economically large and in the order of magnitude of two of the most studied cross-sectional-return premia in finance.

\section{B. Panel Regressions}

A limitation of the portfolio analysis is that returns may differ across portfolios for reasons other than price stickiness, such as heterogeneity in market power or cyclicality of demand. 
I therefore exploit the rich cross-sectional variation in returns, measured price rigidities, and other firm characteristics to differentiate between these alternative explanations. Specifically, I run various panel regressions of annual returns at the firm level, $R_{i, t}$, on the firm-specific measure of price stickiness, $S A U_{i}$, firm- and industry-level controls, $X_{i, n, t}$, and year fixed effects, $\mu_{t}$ :

$$
R_{i, t}=\alpha+\beta_{S A U_{i}} \times S A U_{i}+\sum_{n} \beta_{n} \times X_{i, n, t}+\mu_{t}+\epsilon_{i, t}
$$

Table 4 reports results for annual, non-overlapping percentage returns. Standard errors are clustered at the firm level and reported in parentheses. The coefficient on SAU in column (1) is negative and highly statistically significant: moving from a firm that never changes product prices to a firm with the most flexible prices leads to a return differential of $6 \%$ per year. ${ }^{19}$ Adding year fixed effects in column (2) increases the coefficient on SAU in absolute value. In columns (3)-(5), we see that larger firms have lower returns (size effect); firms with high book value of equity compared to market value command a positive return premium (value effect); and firms with higher $\beta$ s earn on average higher returns $(C A P M)$. Controlling for these factors, however, has little impact on the coefficient on SAU. The coefficient varies between -8.04 and -12.94 , which implies a return differential between sticky- and flexible-price firms of 4.8\%-7.8\% per year. Controlling for additional covariates in columns (6)-(11) has no material effect on the economic or statistical significance of the coefficient of interest. In the last column, I add all explanatory variables jointly. The coefficient on the frequency of price adjustment remains negative and highly statistically significant, contrary to the coefficients on some of the return predictors. The specification with all controls implies an annual return premium of $4.2 \%$. The coefficient on SAU in the panel regressions implies a similar spread in returns as the portfolio analysis in Table 3: the difference in the frequency of price adjustment between the two extreme portfolios of 0.34 (see Table 16 in the appendix) implies a return differential of $2.4 \%-4.4 \%$, depending on the controls employed.

Table 5 repeats the baseline analysis at the industry level to control for possibly unobserved industry heterogeneity. This exercise exploits only variation in the frequency of price adjustment within industry. I typically have fewer observations, and thus my

\footnotetext{
${ }^{19} \mathrm{I}$ calculate this premium by multiplying the regression coefficient on SAU by the difference in the frequency of price adjustment: $10.04 \times 0.6$ (see Table 1 ). The interquartile range in the frequency of price adjustment implies an annual return difference of 1.8\%. A one-standard-deviation change in SAU is associated with a differential return of $1.3 \%$ per year.
} 
estimates have higher sampling uncertainty. For all industries, I find a negative coefficient on SAU, which is statistically significant for three out of the six industries. These results indicate that the baseline effects are not driven by unobserved industry characteristics. Instead of running regressions at the industry level and relying on small sample sizes, I add industry dummies in the last column of Table 5. The coefficient on the frequency of price adjustment is highly statistically significant, economically large, and consistent with previous estimates. The return premium for sticky-price firms is therefore not driven by differences in mean return across industries for reasons orthogonal to the frequency of price adjustment.

\section{Double Sorts}

In Table 6, I perform conditional double sorts to allow for a potential non-linear association between firm characteristics and returns. Specifically, I first sort all stocks into three baskets based on a cross-sectional-return predictor. Within each basket, I further sort stocks into three baskets based on price stickiness. For each category of price stickiness, I then take the average across sorts of the firm characteristic and report them in Table 6. In column (1), for example, I compare portfolios differing in price stickiness but with similar composition of market capitalization.

In column (0), I report the results of an unconditional sort into tertiles based on the frequency of price adjustment. This sorting generates a statistically-significant spread in returns of more than $3 \%$ between the sticky- and flexible-price portfolios. Looking at the sorting conditional on size in column (1), we see that returns decrease monotonically in price flexibility. The spread in returns between sticky- and flexible-price firms is a statistically significant $2.5 \%$ per year. Focusing on this difference across conditioning variables in columns (2)-(9), we see that price stickiness always commands a statistically significant premium between $2.7 \%$ and $3.5 \%$ per year. These premia are similar in size to the unconditional premium in column (0).

To get a feeling for the magnitude of the return differential, I perform two more conditional double sorts in the last two columns. First, I sort all stocks into three brackets based on size. Second, within each size category, I sort stocks based on $\beta$ and bookto-market. These sorts generate an annual return differential between high- and low- $\beta$ stocks and value and growth sorts of $3.5 \%$ and $1.8 \%$, respectively, after controlling for size. The conditional premium for high- $\beta$ stocks is barely statistically significant, and the 
conditional value premium is economically small and statistically insignificant.

The premium for sticky-price firms is hence neither driven by linear nor non-linear relations with standard cross-sectional-return predictors, and is economically significant.

\section{Exposure to Systematic Risk}

At the portfolio level, I test whether the CAPM can explain the cross-sectional-return difference. I then decompose the systematic risk exposure into co-movement with aggregate cash-flow news and discount-rates news, and I study the effects of monetary policy shocks on returns.

\section{D.1 Capital Asset Pricing Model}

To test the CAPM, I perform standard time-series regressions of portfolio excess returns, $R_{p, t}^{e}$, on a constant and the excess returns of the CRSP value-weighted index, $R_{m, t}^{e}$ :

$$
R_{p, t}^{e}=\alpha_{p}+\beta_{p} \times R_{m, t}^{e}+\epsilon_{p, t}
$$

The CAPM predicts that the expected excess return is fully explained by exposure to market risk, namely, that the $\alpha$ is zero.

Table 7 reports $\alpha$ in percent per month and $\beta$ s for the unconditional CAPM in Panel $\mathrm{A}$ and the conditional CAPM in Panel B. ${ }^{20} \mathrm{I}$ evaluate statistical significance using the time-series variability of the slope and intercept coefficients following Fama and MacBeth (1973) in parentheses and Newey and West (1987)-corrected standard errors in brackets.

In Panel A, we see that the unconditional CAPM cannot explain the portfolio returns. Monthly $\alpha$ s range between $0.46 \%$ and $0.57 \%$ per month and are highly statistically significant. In column (6), we also see that the L-H portfolio has a statistically insignificant $\alpha$ of $0.11 \%$ per month.

Panel B shows similar findings for the conditional CAPM: $\alpha$ s are positive and statistically significant but similar across portfolios. $\beta$ s monotonically decrease from 1.29 for portfolio 1 to 0.91 for portfolio 5. The conditional CAPM drives the $\alpha$ of the L-H portfolio all the way to 0 . The difference in annual returns between stocks with high and

\footnotetext{
${ }^{20} \mathrm{I}$ estimate the conditional CAPM monthly on a rolling basis over the previous year, following Lewellen and Nagel (2006). In line with their setup, I add both the contemporaneous and one-month lagged market excess return in the rolling short-window regressions and define the conditional $\beta$ as the sum of the slope coefficients.
} 
low frequencies of price adjustment of more than $4 \%$ is fully explained by their differential exposure to market risk.

Figure 2 plots the excess returns of the L-H portfolio and the aggregate market. The two series track each other closely. Times of low market returns typically coincide with times of low returns to the L-H portfolio. The unconditional correlation between the two times series is more than $50 \%$.

Sticky-price firms are riskier and therefore earn higher returns than firms with flexible prices. ${ }^{21}$ These findings imply that the frequency of price adjustment, a simple measure of a firm's pricing technology, is a significant predictor of systematic risk.

\section{D.2 Discount-Rate and Cash-Flow News}

Differences in the frequency of price adjustment lead to a spread in returns that is fully explained by differential exposure to systematic risk. The empirical success of the CAPM is surprising because the data generally reject this model. ${ }^{22}$ Campbell and Vuolteenaho (2004) argue that variations in the aggregate stock market can occur either due to news about future cash flows or due to news about future discount rates. They derive a decomposition of CAPM $\beta$ into a cash-flow $\beta, \beta_{C F}$, and a discount-rate $\beta, \beta_{D R}$, and they suggest the price of risk for the covariation with discount-rate news is lower than the price of risk for the covariation with cash-flow news based on the insights of the ICAPM. ${ }^{23}$ Differential exposure to these two sources of fundamental risk can explain why the overall $\beta$ might not be a sufficient statistic to explain expected returns. High- $\beta$ stocks can earn lower returns than predicted by the CAPM if most of their overall $\beta$ is due to the covariation with discount-rate news.

In Table 8, I perform the Campbell and Vuolteenaho (2004) decomposition to investigate why the CAPM performs well in my setting.

\footnotetext{
${ }^{21}$ Differences in $\beta \mathrm{s}$ fully explain differences in returns in the portfolio analysis, whereas individual firms' $\beta$ s and the frequency of price adjustment are both individually significant in the panel regressions. Noting that firm-level $\beta \mathrm{s}$ are measured with noise can reconcile this apparent contradiction. The empirical asset-pricing literature has therefore moved away from explaining individual stock returns to explaining returns at the portfolio level sorted on some characteristic of interest (see Fama (1976)).

${ }^{22}$ Frazzini and Pedersen (2013) show that a sorting on pre-formation $\beta$ s leads to a spread in realized $\beta \mathrm{s}$ of 1.18 , which is only associated with a spread in realized returns of 0.06 per month. They call this phenomenon the "too flat security market line."

${ }^{23}$ See Merton (1973), Campbell (1993), and Campbell (1996).
} 
I define cash-flow and discount-rate $\beta \mathrm{s}$ as

$$
\begin{aligned}
\beta_{p, C F} & \equiv \frac{\operatorname{Cov}\left(r_{p, t}^{e}, N_{C F, t}\right)}{\operatorname{Var}\left(r_{m, t}^{e}-\mathbb{E}_{t-1} r_{m, t}^{e}\right)} \\
\beta_{p, D R} & \equiv \frac{\operatorname{Cov}\left(r_{p, t}^{e},-N_{D R, t}\right)}{\operatorname{Var}\left(r_{m, t}^{e}-\mathbb{E}_{t-1} r_{m, t}^{e}\right)},
\end{aligned}
$$

where $r_{p, t}^{e}$ is the log excess return of portfolio $p, r_{m, t}^{e}$ is the log excess return of the market, $N_{C F, t}$ denotes news about future dividends, $N_{D R, t}$ denotes news about future expected returns, and $\mathbb{E}_{t}$ is the expectation operator conditional on the time $t$ information set. I estimate a VAR with the market excess returns as one of the state variables. The news terms are then simple functions of VAR innovations. ${ }^{24}$ I calculate GMM (Hansen (1982)) standard errors conditional on the realized news series from the VAR.

We see in column (1) that cash-flow and discount-rate news contribute almost equally to the overall $\beta$ of the sticky-price portfolio of $1.15: \beta_{S 1, C F}$ is 0.55 and $\beta_{S 1, D R}$ is 0.60 . Both $\beta$ s decrease monotonically in the portfolio number to values of 0.41 and 0.44 , respectively. The difference in $\beta$ s between sticky- and flexible-price portfolios is 0.14 for $\beta_{S 1-S 5, C F}, 0.15$ for $\beta_{S 1-S 5, D R}$, and 0.29 for the overall $\beta_{S 1-S 5}$. The difference in discount-rate and cash-flow $\beta \mathrm{s}$ is almost constant across portfolios and varies between 0.03 and 0.04 . Sticky price firms have higher exposure to both sources of fundamental risk and are unambiguously riskier than firms with flexible prices. The overall $\beta$ is therefore sufficient to determine the overall riskiness of a portfolio independent of potentially different prices of risk. ${ }^{25}$

\section{D.3 Monetary Policy Shocks and Portfolio Returns}

There is a growing literature documenting the importance of monetary policy for risk premia in equity and bond markets. Sixty to eighty percent of the realized equity premium is earned around macroeconomic news announcements such as the press releases

\footnotetext{
${ }^{24}$ See the appendix for a detailed discussion and derivation of the key equations.

${ }^{25}$ The reason for the good empirical performance of the CAPM is in line with the findings of Campbell and Vuolteenaho (2004). They document that the CAPM can explain the cross section of size and book-to-market sorted portfolios for a sample from 1928 to 1963 as both discount-rate and cash-flow $\beta$ s line up with the overall $\beta$ s.
} 
of the Federal Open Market Committee (FOMC). ${ }^{26}$ Monetary policy surprises are purely nominal shocks and are of particular interest in the context of nominal rigidities. A further advantage of monetary policy shocks is that they are easy to construct, well identified, and are the subject of a substantial literature in macroeconomics and finance. In addition, these shocks are the main driver of risk premia in my model.

Table 9 reports the results from regressing monthly excess returns, $R_{p, t}^{e}$, of portfolios sorted on the frequency of price adjustment and the CRSP value-weighted index on the surprise component of the one-month change in the Federal Funds rate, $\Delta i_{t}^{u}$ :

$$
R_{p, t}^{e}=\alpha_{p}+\beta_{p, F F R} \times \Delta i_{t}^{u}+\epsilon_{p, t} .
$$

The sample is restricted to a period from June 1989 to June 2007 due to the availability of the Federal Funds futures. The aggregate market falls by more than $9 \%$ after a $1 \%$ surprise increase in the Federal Funds rate (column (1)). The reaction varies substantially across portfolios. Portfolio 1 is the most responsive (falls by $11 \%$ ), whereas the flexible price portfolio falls by only $5 \%$.

This differential reaction is broadly in line with CAPM. The sticky-price portfolio is predicted to earn $-11 \%$ following a Federal Funds rate surprise. ${ }^{27}$ The predicted sensitivities decrease monotonically in the degree of price stickiness to a predicted drop of $7 \%$ for the flexible-price portfolio. The CAPM slightly underpredicts the cross-sectional dispersion in returns following the Federal Funds rate surprises. This "too flat Capital Market Line" phenomenon is, however, an order of magnitude smaller than the one documented in Frazzini and Pedersen (2013). Therefore, the CAPM has high explanatory power for the cross section of stocks sorted on the frequency of price adjustment, both unconditionally and conditional on the realization of monetary policy shocks. These results underline the role of the frequency of price adjustment as a strong determinant of the cross section of stock returns.

\footnotetext{
${ }^{26}$ Bernanke and Kuttner (2005) show that a $1 \%$ surprise increase in the Federal Funds rate leads to a drop in the CRSP value-weighted index of more than $11 \%$ in monthly time-series regressions. Savor and Wilson (2013) show that $60 \%$ of the equity premium is earned around scheduled macroeconomic news announcements, whereas Lucca and Moench (2013) find that 80\% of the equity premium since 1994 is earned in the 24 hours before the FOMC press releases. On the contrary, Campbell, Pflueger, and Viceira (2013) study the impact of monetary policy and macroeconomic shocks on nominal bond premia and the interlinkages with equity markets.

${ }^{27}$ To calculate the predicted reactions, I first re-estimate the CAPM $\beta$ s and I then multiply the $\beta$ s and the estimated sensitivity of the CRSP value-weighted index.
} 


\section{E. Business-Cycle Variation in Return Premium}

A large literature in finance documents variation in expected excess returns over time, which is predictable by scaled stock-price ratios. ${ }^{28}$ Lustig and Verdelhan (2012) show that excess returns in the United States and other OECD countries are substantially higher during recessions than during expansions. Variation in risk premia leads to variation in the cost of capital of firms to evaluate investment projects and has important implications for asset allocation and market-timing investment strategies. Hence variation in return premia are of interest for both macroeconomists and financial economists.

To test whether returns of the L-H portfolio vary systematically with business-cycle conditions, I perform long-horizon forecasting regressions. Specifically, I run m-month forecasting regressions of cumulative log excess returns of the L-H portfolio, $r_{l h}^{e}$, on the $\log$ dividend-price ratio for the CRSP value-weighted index, $d p$ in Panel A, the break-adjusted log dividend-price ratio in Panel B following Lettau and Van Nieuwerburgh (2008), and the proxy for the consumption-wealth ratio of Lettau and Ludvigson (2001), cay, ${ }^{29}$ in Panel C:

$$
\sum_{s=1}^{m} r_{l h, t+s}^{e}=a_{l h}+b_{l h}^{(m)} d p_{t}+\epsilon_{t+m}
$$

with similar definitions for the break-adjusted dividend-price ratio and cay.

The rationale behind these regressions is the Campbell and Shiller (1988a) approximation for the log dividend-price ratio. They show that variation in the dividend-price ratio implies predictability of future returns or dividend growth (or an explosive dividend-price ratio). Empirically, the whole variation in the dividend-price ratio comes from variation in expected returns. Low prices and, hence, high dividend-price ratios predict high returns in the future.

Table 10 reports regression coefficients for horizons ranging from one month to five years. For each regression, the table reports OLS standard errors in parentheses, Newey and West (1987) standard errors in brackets, Hansen and Hodrick (1980) standard errors

\footnotetext{
${ }^{28}$ See, among many, Fama and French (1988), Campbell and Shiller (1988b), Campbell (1991), Cochrane (2008), Lettau and Ludvigson (2005), and Koijen and Van Nieuwerburgh (2011) for an excellent recent overview of this literature.

${ }^{29}$ Lettau and Ludvigson (2001) use quarterly data from the National Income and Product Accounts to construct cay. To get a monthly series, I linearly interpolate the quarterly observations available under http://faculty.haas.berkeley.edu/lettau/data_cay.html. cay is the co-integration residual of consumption (c), asset wealth (a), and labor income (y). They show that it is the asset wealth component which error corrects after a deviation from the equilibrium relation which is therefore predictable.
} 
in curly brackets, and Hodrick (1992) standard errors in angle brackets. ${ }^{30}$ Consistent with recent findings for the aggregate stock market (see, e.g., Lettau and Ludvigson (2005)), the log dividend-price ratio has no explanatory power for the L-H portfolio. Lettau and Van Nieuwerburgh (2008) argue that structural changes in the economy have caused the extreme persistence of the dividend-price ratio. This high persistence might explain the failure of the ratio to predict future returns. They recommend using a break-adjusted dividend-price ratio to account for these shifts. Following their procedure, I find evidence for predictability of the L-H portfolio returns at horizons between three to five years. High dividend-price ratios predict positive returns for the L-H portfolio.

Lettau and Ludvigson (2005) show that cay is less persistent and that it drives out the log dividend-price ratio in predicting the aggregate stock market at business-cycle frequencies. In Panel C, we see cay has strong predictive power for the L-H portfolio at all horizons and explains $60 \%$ of the time-series variation at a three-year horizon. ${ }^{31}$ In times of a high consumption-wealth ratio, the $\mathrm{L}-\mathrm{H}$ portfolio has high expected returns going forward.

Figure 3 plots cay at the end of June along with the subsequently realized five-years returns of the L-H portfolio. The two times series track each other fairly closely. Times of low asset returns and hence high values of cay predict high future returns of the L-H portfolio. The raw correlation between the two time series is a remarkable $68.73 \%$.

The results from the long-horizon predictive regressions establish that firms with sticky prices have higher expected returns than firms with flexible prices in recessions and in times of low aggregate stock market returns. The higher cost of capital for these firms in bad times has implications for firms' investment decisions and the portfolio allocation and market-timing strategies of investment professionals. ${ }^{32}$

\footnotetext{
${ }^{30}$ The overlapping nature of returns in long-horizon regressions induces serial correlation in the error terms. Hansen and Hodrick (1980) and Hodrick (1992) standard errors offer alternative methods to take this feature of the error terms into account.

${ }^{31}$ cay has a marginally statistically significant forecasting power for the log excess return of the CRSP value-weighted index. The maximal $R^{2}$ is $35 \%$ at a four-year horizon (see Table 33 in the appendix).

${ }^{32}$ The appendix contains additional results. Specifically, I report results for my baseline panel regression specification for overlapping annual returns at the monthly frequency, annualized monthly returns, as well as the previous specification with month fixed effects. The appendix also contains results of panel regressions for the full sample, for the benchmark sample with unwinsorized variables and for panel regressions at the portfolio level. I also discuss results for realized volatilities and for different measures of the frequency of price adjustment, both at the portfolio level for raw and characteristic adjusted returns and in panel regressions. In addition, I report descriptive statistics at the portfolio level and for the full sample. All additional results are similar to those reported in the main body of the paper and discussed in detail in Section $F$. of the appendix.
} 
The findings in this section document that the cross-sectional-return premium for firms with sticky product prices is a compensation for risk. The portfolio of stocks with low frequencies of price adjustment has a higher co-movement with the aggregate stock market than the flexible-price portfolio. This return premium varies systematically with business-cycle conditions. In the next section, I develop a multi-sector production-based asset-pricing model to rationalize this return premium theoretically. The only source of heterogeneity across sectors is a varying degree of price stickiness. Key ingredients to quantitatively replicate the empirical results are a sufficiently high elasticity of substitution of consumption varieties within sector for the cross-sectional-return premium. Habit formation as well as wage stickiness are crucial for the level and the predictability of equity returns.

\section{Model}

In this section, I develop a production-based asset-pricing model. Households have external habit formation in consumption and derive utility from a composite consumption good and leisure. They provide different labor services and have market power in setting wages. The production side of the economy is organized in different sectors producing output according to a technology that is linear in labor. Individual firms in each sector are monopolistically-competitive suppliers of differentiated goods and competitive demanders in the market of homogeneous labor input. I consider a cashless economy with nominal bonds in zero net supply. The monetary authority sets short-term interest rates according to a Taylor rule. My model features nominal rigidities at the micro level that are necessary to explain the real effects of purely nominal shocks. Specifically, the model exhibits sticky wages and prices. I assume equal wage rigidities across sectors but differing degrees of price stickiness, in line with micro evidence of Nakamura and Steinsson (2008). This empirically motivated setup allows me to theoretically investigate the impact of the heterogeneity in price stickiness on the cross section of stock returns.

\section{A. Firms}

There is a continuum of monopolistically-competitive firms divided into different sectors. Firms are indexed by their sector, $k \in[0,1]$, and by $j \in[0,1]$. The distribution of firms across sectors is given by the density $f$ on $[0,1]$. Firms have market power and 
follow time-dependent pricing rules. The time for price adjustment arrives stochastically. Each period, a fraction $1-\theta_{k}$ of firms in sector $k$ adjusts prices. The probability of price adjustment, or Calvo (1983)-rate, is equal across firms in a given sector and is independent of the time the price has been in effect. ${ }^{33}$ These probabilities determine the fraction of price adjusters in the aggregate, the individual firm probabilities of price adjustment in any given period, and the average duration of price spells. Firms are demand constrained and satisfy all demand at posted prices. They rent homogeneous labor services, $H_{t}$, taking the wage rate, $W_{t}$, as given to produce output according to a linear technology,

$$
Y_{k j, t}=A_{t} H_{k j, t}
$$

where $A_{t}=\exp \left(a_{t}\right)$ is aggregate technology evolving according to

$$
a_{t+1}=\rho_{a} a_{t}+\sigma_{a} \varepsilon_{a, t+1} .
$$

$\rho_{a}$ is the autoregressive coefficient of $\log$ technology, $\varepsilon_{a, t+1}$ is an i.i.d. standard normal random variable and, $\sigma_{a}$ is the standard deviation of the technology shock.

The pricing problem of a firm that adjusts in period $t$ is then to set the reset price $X_{k j, t}$ to maximize the expected present value of discounted profits over all future histories in which it will not have a chance to adjust the price:

$$
\begin{gathered}
\mathbb{E}_{t} \sum_{s=0}^{\infty}\left(\beta \theta_{k}\right)^{s} \frac{\Lambda_{t+s}}{\Lambda_{t}}\left(X_{k j, t} Y_{k j, t+s}-W_{t+s} H_{k j, t+s}\right) \\
\text { s.t. } \quad Y_{k j, t+s}=\left(\frac{X_{k j, t}}{P_{k, t+s}}\right)^{-\varepsilon_{c k}}\left(\frac{P_{k, t+s}}{P_{t+s}}\right)^{-\varepsilon_{c}} Y_{t+s} \\
Y_{k j, t+s}=A_{t+s} H_{k j, t+s},
\end{gathered}
$$

where $\Lambda_{t}$ equals the Lagrange multiplier on the household budget constraint, $\varepsilon_{c}$ and $\varepsilon_{c k}$ are the elasticities of substitution in consumption between sectoral subcomposites and within-sector consumption varieties, $P_{t}$ and $P_{k, t}$ are the composite and sector price indexes defined below, and $Y_{t}$ is aggregate output. Equation (2) represents the demand for consumption variety $k j$ derived below after imposing market clearing in the goods

\footnotetext{
${ }^{33}$ The Calvo (1983) model is the workhorse New Keynesian model because it is tractable and easily allows aggregation. Modeling price adjustment in a state-dependent framework instead of a time-dependent fashion has very similar implications for macroeconomic aggregates in times of low and stable inflation (see Dotsey, King, and Wolman (1999)).
} 
market.

The first-order condition with respect to $X_{k j, t}$ yields $^{34}$

$$
\frac{X_{k j, t}}{P_{t}}=\frac{\varepsilon_{c k}}{\varepsilon_{c k}-1} \frac{\mathbb{E}_{t} \sum_{s=0}^{\infty}\left(\beta \theta_{k}\right)^{s} \frac{\lambda_{t+s}}{\lambda_{t}}\left\{\left(\frac{W_{t+s}}{P_{t+s}}\right)\left(\frac{1}{A_{t+s}}\right)\left(\frac{P_{k, t+s}}{P_{t+s}}\right)^{\varepsilon_{c k}}\left(\frac{P_{k, t+s}}{P_{t+s}}\right)^{-\varepsilon_{c}}\left(\frac{P_{t}}{P_{t+s}}\right)^{-\varepsilon_{c k}} Y_{t+s}\right\}}{\mathbb{E}_{t} \sum_{s=0}^{\infty}\left(\beta \theta_{k}\right)^{s} \frac{\lambda_{t+s}}{\lambda_{t}}\left\{\left(\frac{P_{k, t+s}}{P_{t+s}}\right)^{\varepsilon_{c k}}\left(\frac{P_{k, t+s}}{P_{t+s}}\right)^{-\varepsilon_{c}}\left(\frac{P_{t}}{P_{t+s}}\right)^{1-\varepsilon_{c k}} Y_{t+s}\right\}},
$$

where $\lambda_{t}=\Lambda_{t} P_{t}$. Firms charge effectively a constant markup, $\varepsilon_{c k} /\left(\varepsilon_{c k}-1\right)$, over a weighted average of current and future real marginal costs. Adjusting firms take into account that they might not have a chance to reset prices in future periods. For example, they set higher prices in case they expect higher marginal costs in the future in order to not sell at a loss in those periods. The Calvo (1983)-probabilities distort the discount factor: the probability that a price set today will still be in effect in period $\mathrm{t}+\mathrm{s}$ is $\theta_{k}^{s}$. Firms therefore heavily discount the effect of future economic conditions for setting current prices if they have a high probability of price adjustment, $\left(1-\theta_{k}\right)^{s}$.

Adjusting firms in sector $k$ set prices according to equation (3), taking the prices of other firms and aggregate prices as given. All price adjusters in a given sector, however, choose identical prices by the symmetry of the problem. Therefore, I can express the optimal reset price in sector $k$ as

$$
\frac{X_{k, t}}{P_{t}}=\frac{\varepsilon_{c k}}{\varepsilon_{c k}-1} \frac{F_{p, k, t}}{K_{p, k, t}}
$$

where $F_{p, k, t}$ and $K_{p, k, t}$ are functions of sector $k$ variables only and follow simple recursions. Absent the Calvo (1983) friction, all firms set prices as a markup over current-period marginal costs:

$$
\frac{X_{t}}{P_{t}}=\frac{\varepsilon_{c k}}{\varepsilon_{c k}-1} \frac{1}{A_{t}} \frac{W_{t}}{P_{t}}
$$

The Calvo (1983) setup allows me to write the sectoral price index as a weighted average of last period's price index and period t's optimal reset price with weights corresponding

\footnotetext{
${ }^{34}$ Detailed derivations are generally delegated to the appendix.
} 
to the fraction of price (non-)adjusters:

$$
P_{k, t}=\left[\left(1-\theta_{k}\right) X_{k, t}^{1-\varepsilon_{c k}}+\theta_{k} P_{k, t-1}^{1-\varepsilon_{c k}}\right]^{\frac{1}{1-\varepsilon_{c k}}}
$$

The value of the firm with current price $P_{k j, t}$ can be written as a simple function of sector $k$ variables:

$$
V\left(P_{k j, t}\right)=\mathbb{E}_{t}\left\{\frac{1}{\lambda_{t}} P_{t}\left[R S_{k, t}\left(\frac{P_{k j, t}}{P_{t}}\right)^{1-\varepsilon_{c k}}-C S_{k, t}\left(\frac{P_{k j, t}}{P_{t}}\right)^{-\varepsilon_{c k}}+R F_{k, t}-C F_{k, t}\right]\right\}
$$

where $R S_{k, t}, C S_{k, t}, R F_{k, t}$ and $C F_{k, t}$ are the revenues (R) and costs (C) coming from expected price stickiness $(\mathrm{S})$ and flexibility $(\mathrm{F})$, respectively, and follow simple recursions.

\section{B. Households}

There is a large number of identical, infinitely lived households. Households have a love for variety and derive utility from many different consumption goods. Each household supplies all types of differentiated labor services, $h_{i, t}, i \in[0,1]$.

The representative household has additively separable utility in consumption and leisure and maximizes

$$
\begin{aligned}
& \quad \mathbb{E}_{t} \sum_{s=0}^{\infty} \beta^{s}\left[\frac{\left(C_{t+s}-b C_{t+s-1}\right)^{1-\gamma}}{1-\gamma}-\psi_{L} \int_{0}^{1} \frac{h_{i, t+s}^{1+\sigma}}{1+\sigma} \mathrm{d} i\right] \\
& \text { s.t. } \quad P_{t} C_{t}=\int_{0}^{1} W_{i, t} h_{i, t} \mathrm{~d} i+R_{t-1} B_{t-1}-B_{t}+D_{t},
\end{aligned}
$$

where $\beta$ is the subjective discount factor, $C_{t}$ is the composite consumption good defined below, $b \geq 0$ is a habit-persistence parameter in consumption, $h_{i, t}$ denotes hours worked of type $i, \psi_{L} \geq 0$ is a parameter, $W_{i, t}$, nominal wage for labor type $i, R_{t}$ is the gross nominal interest rate, $B_{t}$ denotes nominal bond holdings, and $D_{t}$ is aggregate dividends from the firm sector. Profits are redistributed via lump-sum transfer at the end of each period. The parameters $\gamma$ and $\sigma$ denote the coefficient of relative risk aversion and the inverse of the Frisch elasticity of labor supply, respectively. The per-period budget constraint states that total consumption expenditure equals total disposable income, which consists of labor income from the different labor types, and gross payoffs from previous-period 
bond holdings net of new bond purchases plus aggregate dividends.

The composite consumption good is a Dixit-Stiglitz aggregate of many individual goods:

$$
\begin{aligned}
C_{t} & =\left[\int_{0}^{1} f(k)^{\frac{1}{\varepsilon_{c}}} C_{k, t}^{\frac{\varepsilon_{c}-1}{\varepsilon_{c}}} \mathrm{~d} k\right]^{\frac{\varepsilon_{c}}{\varepsilon_{c}-1}} \\
C_{k, t} & =f(k)\left[\int_{0}^{1} C_{k j, t}^{\frac{\varepsilon_{c k}-1}{\varepsilon_{c k}}} \mathrm{~d} j\right]^{\frac{\varepsilon_{c k}}{\varepsilon_{c k}-1}} .
\end{aligned}
$$

$C_{k, t}$ is the subcomposite produced by firms in sector $k$, and $C_{k j, t}$ is the variety produced by firm $j$ in sector $k$.

The consumption price indexes $P_{t}$ and $P_{k, t}$ are given by

$$
\begin{aligned}
P_{t} & =\left[\int_{0}^{1} f(k) P_{k, t}^{1-\varepsilon_{c}} \mathrm{~d} k\right]^{\frac{1}{1-\varepsilon_{c}}} \text { and } \\
P_{k, t} & =\left[\int_{0}^{1} P_{k j, t}^{1-\varepsilon_{c k}} \mathrm{~d} j\right]^{\frac{1}{1-\varepsilon_{c k}}} .
\end{aligned}
$$

The demand for individual consumption varieties depends on relative prices

$$
\begin{aligned}
C_{k, t} & =f(k) C_{t}\left(\frac{P_{k, t}}{P_{t}}\right)^{-\varepsilon_{c}} \text { and } \\
C_{k j, t} & =f(k)^{-1} C_{k, t}\left(\frac{P_{k j, t}}{P_{k, t}}\right)^{-\varepsilon_{c k}} .
\end{aligned}
$$

\section{Wage Rate}

The structure of the labor market follows Erceg, Henderson, and Levin (2000). The representative household sells labor services to a representative, competitive labor aggregator. The aggregator transforms the different labor types into aggregate labor input, $H_{t}$. Homogeneous labor is a Dixit-Stiglitz aggregate of the different labor types

$$
H_{t}=\left[\int_{0}^{1} h_{i, t}^{\frac{\varepsilon_{w}-1}{\varepsilon_{w}}} d i\right]^{\frac{\varepsilon_{w}}{\varepsilon_{w}-1}}
$$

where $\varepsilon_{w} \geq 1$ is the elasticity of substitution between labor types.

The aggregator minimizes the cost of producing a given quantity of aggregate labor, taking the wage rates of the individual labor types as given. It sells homogeneous labor 
input to individual firms at their unit cost, or equivalently, the aggregate wage rate, $W_{t}$ :

$$
W_{t}=\left[\int_{0}^{1} W_{i, t}^{1-\varepsilon_{w}} d i\right]^{\frac{1}{1-\varepsilon_{w}}}
$$

The demand curve for labor of type $i, h_{i, t}$, is downward sloping and given by

$$
h_{i, t}=\left(\frac{W_{i, t}}{W_{t}}\right)^{-\varepsilon_{w}} H_{t}
$$

For each labor type $i$, a monopoly union represents all workers of this type. Individual unions set wages optimally, subject to a Calvo (1983)-style wage friction. Each period, a fraction $1-\theta_{w}$ of labor unions re-optimizes nominal wages.

The optimization problem of adjusting unions is given by

$$
\begin{array}{r}
\mathbb{E}_{t} \sum_{s=0}^{\infty}\left(\beta \theta_{w}\right)^{s}\left\{-\psi_{L} \frac{h_{i, t+s}^{1+\sigma}}{1+\sigma}+\frac{\Lambda_{t+s}}{\Lambda_{t}} U_{i, t} h_{i, t+s}\right\} \\
\text { s.t. } \quad h_{i, t+s}=\left(\frac{U_{i, t}}{W_{t+s}}\right)^{-\varepsilon_{w}} H_{t+s}
\end{array}
$$

where $U_{i, t}$ is the optimal reset wage.

Unions set wages to equalize the expected discounted marginal disutility of providing one additional unit of labor to its expected discounted utility. Again, the optimal reset wage is identical for all unions resetting wages in period t. Therefore, I can express the real reset wage as

$$
\left(\frac{U_{t}}{P_{t}}\right)^{1+\varepsilon_{w} \sigma}=\frac{\varepsilon_{w}}{\varepsilon_{w}-1} \psi_{L}\left(\frac{W_{t}}{P_{t}}\right)^{\varepsilon_{w} \sigma} \frac{F_{w, t}}{K_{w, t}}
$$

where $F_{w, t}$ and $K_{w, t}$ follow simple recursions.

In case of perfectly flexible wages, the optimal real reset wage equals a constant markup, $\varepsilon_{w} /\left(\varepsilon_{w}-1\right)$, times the marginal rate of substitution between labor and consumption:

$$
\frac{U_{t}}{P_{t}}=\frac{\varepsilon_{w}}{\varepsilon_{w}-1} \frac{\psi_{L} h_{i, t}^{\sigma}}{\lambda_{t}}
$$




\section{Monetary Policy}

The monetary authority sets the short-term nominal interest rate according to

$$
i_{t}=\phi_{\pi} \pi_{t}+\phi_{x} x_{t}+\log \left(\frac{1}{\beta}\right)+u_{m, t}
$$

where $i_{t}$ is $\log R_{t}, \pi_{t}=\log P_{t}-\log P_{t-1}$ is aggregate inflation, $x_{t}=\log Y_{t}-\log Y_{t-1}$ growth in output, $\phi_{\pi}$ and $\phi_{x}$ are parameters, and $u_{m, t}$ is a monetary policy shock. ${ }^{35}$ The policy shock follows

$$
u_{m, t}=\rho_{m} u_{m, t-1}+\sigma_{m p} \varepsilon_{m p, t+1} .
$$

$\rho_{m}$ is the autoregressive coefficient of the monetary policy shock, $\varepsilon_{m p, t+1}$ is an i.i.d. standard normal random variable and $\sigma_{m p}$ is the standard deviation of the policy shock.

\section{E. Equilibrium}

General equilibrium is defined by the optimality conditions for the household utilitymaximization problem, by every firm $k j$ 's profit optimization, by market clearing in the product, labor, and financial markets, and by rational expectations. Product-market clearing requires $C_{k j, t}=Y_{k j, t}$ for all consumption varieties. Labor-market clearing imposes $L_{t}=\int_{0}^{1} h_{i, t} \mathrm{~d} i=\int_{0}^{1} \int_{0}^{1} H_{k j, t} \mathrm{~d} j \mathrm{~d} k$. Bond-market clearing requires $B_{t}=0$, that is, the interest rate set by the monetary authority is in line with the household's optimization problem.

\section{F. Inefficiency}

Knowledge of aggregate labor input, $L_{t}$, is not sufficient to determine aggregate output. Cross-sectional dispersion of wage rates across different labor types and product prices within and across sectors increase the required amount of labor input for the production of a given level of the aggregate output index. Different labor types are imperfect substitutes in production, whereas different consumption varieties are imperfect substitutes in the consumption index. As each labor type enters the labor aggregator and the household's

\footnotetext{
${ }^{35}$ Walsh (2003) and Orphanides and Williams (2006) highlight the role of output growth for stabilizing purposes instead of the output gap which might be difficult to measure accurately in real time. Coibion and Gorodnichenko (2011), on the contrary, show that a central bank responding to output growth instead of the output gap makes determinacy of equilibrium more likely.
} 
utility function symmetrically, optimality requires equal hours across types. Equivalently, as different consumption varieties enter the consumption index symmetrically and firms face identical production technologies, an optimal allocation requires equal production across firms. After a shock, some firms and unions are unable to adjust their product prices and wages, respectively, which leads to dispersion in prices and wages. Wage dispersion across different labor types increases the required amount of labor types for a given level of homogeneous labor. Price dispersion increases the required amount of homogeneous labor for a given level of the output index. Price and wage dispersion and hence aggregate inefficiency increase in the curvature of the respective aggregators, that is, the elasticity of substitution across different labor types and the elasticities of substitution of consumption within and across sectoral varieties (see equations (7), (8), and (9)). Inefficiencies across sectors are driven by the elasticity of substitution of consumption varieties within sector as wage dispersion is identical across sectors. The more elastic the demand is for varieties of a given sector and the lower the frequency of price adjustment, the larger the price dispersion (see Woodford (2003)).

\section{G. Calibration}

I calibrate a five-sector version of the model at quarterly frequency to compare the implications of differences in the frequency of price adjustment on stock returns to my empirical findings. I use standard parameter values in the literature (see Table 11). Specifically, the subjective discount factor $\beta$ is 0.99 , implying an annual risk-free rate of $4 \%$ in the non-stochastic steady state. I employ the estimate for the habit-persistence parameter $b=0.76$ from Altig, Christiano, Eichenbaum, and Linde (2011), which is

similar to other estimates in the literature (e.g., Smets and Wouters (2007)). I set the parameters of the utility function $\gamma=5$ and $\psi=1$ following Jermann (1998) and Altig et al. (2011), and I calibrate the inverse of the Frisch elasticity of labor supply, $\sigma$, to a value of 2.5. I set the elasticity of substitution of within-sector consumption varieties and across sectoral subcomposites, $\varepsilon_{c k}$ and $\varepsilon_{c}$, to values of 12 and 8, respectively, following Carvalho (2006). The sectoral elasticity implies a steady-state markup of roughly $9 \%$, in line with empirical evidence by Burnside (1996) and Basu and Fernald (1997). I follow Erceg et al. (2000) and set $\theta_{w}$ to a value of 0.825, in line with estimates of Heer, Klarl, and Maussner (2012) and the empirical literature (see Taylor (1999)). This value implies an average duration of wage contracts of five quarters. $\varepsilon_{w}$ is calibrated to a value of 8 , which 
corresponds to a wage markup of $14 \%$ in the range of estimates used in the literature. ${ }^{36} \mathrm{I}$ set the parameter values of the monetary policy reaction function, $\phi_{\pi}$ and $\phi_{y}$, to standard values of 1.24 and $0.33 / 4$, respectively, in line with results reported in Rudebusch (2002). I use the empirical distribution of the frequencies of price adjustment of Nakamura and Steinsson (2008) to calibrate $\left\langle 1-\theta_{k}\right\rangle_{k=1}^{5}$, and I follow Carvalho (2006) to calibrate the density function $f(k)=1 / 5$, giving equal weight to each sector. In particular, I sort industries by their frequency of price adjustment and construct five synthetic sectors. The sectors correspond to the quintiles of the distribution of the frequency of price adjustment observed in the data. Each sector covers one fifth of consumer spending. The Calvo rates of price adjustment range from 0.105 to 0.985 per quarter. I calibrate the autoregressive parameters of the two shock processes to $\rho_{a}=0.95$ and $\rho_{m}=0.90$ - well within the range of empirical estimates (e.g., Smets and Wouters (2007) and Coibion and Gorodnichenko (2012)). I set the standard deviations of the shocks, $\sigma_{a}$ and $\sigma_{m p}$, to 0.0085 to match the historical standard deviation of log quarterly real gross domestic product (GDP) for my sample period. ${ }^{37}$

In the benchmark case, I solve the model numerically using a second-order approximation as implemented in dynare, and simulate the model for 400 firms in each sectors and 500 periods, discarding the first 250 periods as burn in. ${ }^{38}$ For each firm and time period, I then calculate the firm value, $V\left(P_{k j, t}\right)$, dividends, $D\left(P_{k j, t}\right)$, and returns as $R_{k j, t}=\frac{V\left(P_{k j, t}\right)}{V\left(P_{k j, t-1}\right)-D\left(P_{k j, t-1}\right)}$.

\section{G.1 Simulation Results}

Table 12 reports annualized mean excess returns over the risk-free rate at the sector level, the spread in mean returns between the portfolios containing firms with low and high frequencies of price adjustment, and the annualized equity risk premium and Sharpe

\footnotetext{
${ }^{36}$ Altig et al. (2011) set the wage markup to $5 \%$, whereas Erceg et al. (2000) calibrate $\varepsilon_{w}$ to 4 , implying a markup of $33 \%$. As displayed in Table 12 and Table 36 in the appendix, results are not very sensitive to changes in this parameter.

${ }^{37}$ I download real GDP from the FRED database of the Federal Reserve Bank of St. Louis with series-ID GDPC1. This series is seasonally adjusted at an annual rate and expressed in billions of chained 2009 dollars. The standard deviation of Hodrick-Prescott-filtered log quarterly real GDP is 0.0095 in the data and 0.0102 in the model. Consistent with findings of Gorodnichenko and $\mathrm{Ng}$ (2010), I apply the Hodrick-Prescott filter with a smoothing parameter of 1600 to both historical and model-generated data to calibrate the shock standard deviations.

${ }^{38} \mathrm{I}$ employ the pruning package of Andreasen, Fernández-Villaverde, and Rubio-Ramírez (2013) to ensure the simulated sample paths do not explode. Pruning leaves out terms of higher order than the approximation order.
} 
ratio, as well as the regression coefficient of annualized returns at the firm level on the monthly frequency of price adjustment

$$
R_{k j, t}=\alpha+\beta \times\left(1-\theta_{k}\right)+\epsilon_{k j, t} .
$$

The baseline calibration in line (1) results in annualized excess returns of almost $8 \%$ for the sticky-price sector. Excess returns decrease monotonically in the degree of price flexibility to as low as $5.5 \%$ for the flexible-price sector. The return differential between the sticky- and flexible-price sectors is almost $2.4 \%$ per annum, in line with my empirical findings in Table 4. The model displays an equity premium of $6.6 \%$ and an annual Sharpe ratio of 0.39 . The coefficient of annual firm-level returns on the frequency of price adjustment is negative and highly statistically significant. The coefficient implies that moving from a firm with totally sticky prices to a firm with totally flexible prices is associated with a decrease in annual returns of $2.5 \%$ per annum.

The baseline calibration documents that heterogeneity in the frequency of price adjustment leads to a cross-sectional difference in returns. The following lines of Table 12 evaluate the robustness of this finding and carve out the key driving forces behind this result. Lines (2) and (3) look at specifications in which all sectors have identical frequencies of price adjustment. In line $(2),\left\langle 1-\theta_{k}\right\rangle_{k=1}^{5}=0.77$, which implies the same average duration of price spells across sectors as the baseline calibration, and line (3) looks at an economy with flexible prices. All sectors earn similar returns with an equity premium of $7 \%$ and $7.5 \%$ per year, respectively.

In lines (4) and (5), I investigate the importance of differential elasticities of substitution across and within sector consumption varieties. Increasing the elasticity of substitution of across-sector varieties, $\varepsilon_{c}$, to 12 has no effect on the return differential and leaves the overall equity premium largely unchanged. On the other hand, lowering $\epsilon_{c k}$ to a value of 8 eliminates the cross-sectional difference in returns. These results indicate that the difference in elasticities is not what drives the premium for price stickiness in firm-level simulations, but rather it is the absolute size of the elasticity of substitution of within-sector consumption varieties. I will come back to this finding below.

The following four lines ((6)-(9)) further investigate the impact of within- and acrosssector elasticities on the equity premium and the return differential. In lines (6) and (7), we see that changes in $\epsilon_{c k}$ have an immediate effect on the premium for sticky-price firms while hardly affecting the overall level of the equity premium. In particular, increasing $\epsilon_{c k}$ 
from a baseline value of 12 to 13 increases the cross-sectional spread in returns by almost $50 \%$. On the other hand, varying the across-sector elasticity of substitution (lines (8) and (9)) has only small effects on the level of the risk premium or the cross-sectional-return difference. In lines (10) and (11), we see that lowering the elasticity of substitution between different labor types has only negligible effects, whereas calibrating the Frisch elasticity of labor supply to a value of 1 increases both the cross-sectional spread in returns and the overall equity premium.

In the next exercise, I evaluate the effects of higher aggregate risk. Specifically, I increase the standard deviations for both the monetary policy and the technology shocks. Higher aggregate risk increases the returns for all sectors, but disproportionately for sectors with lower frequencies of price adjustment. The premium for sticky-price firms doubles and the equity premium increases by almost $1 \%$ per year. In the following line, I investigate whether the accumulation of higher-order terms has any effect on my results. ${ }^{39}$ If I do not discard terms of higher order than the desired level of approximation, I find that the cross-sectional-return difference is magnified, whereas the overall equity premium decreases.

Lines (14) and (15) check how changes in the responsiveness of monetary policy affect the findings. A more aggressive stance on inflation dampens the equity premium by $1 \%$ and reduces the dispersion in returns across sectors by a factor of four. Changes in the reaction to output growth, however, have little impact on stock returns. Lines (16) and (17) disentangle the contributions of the two shocks: the cross-sectional and the level effects are almost exclusively driven by monetary policy shocks.

Increasing the persistence of technology shocks in line (18) increases the crosssectional premium for price stickiness and the overall level of the equity premium. Finally, Coibion and Gorodnichenko (2012) show that the persistence of monetary policy in the Greenspan and Bernanke era is better described by interest-rate smoothing than by persistent shocks. Modeling policy inertia via interest-rate smoothing has no impact on my findings.

\footnotetext{
${ }^{39} \mathrm{Kim}$, Kim, Schaumburg, and Sims (2008) coin the notion of garbage terms for terms with higher-order effects than the approximation order and show that accumulation of these terms deteriorates the accuracy of the approximation and leads to explosive sample paths in simulations. The current exercise also runs into the problem of explosive sample paths using an unpruned system and a second-order approximation, which is why I report the results of a third-order approximation.
} 


\section{G.2 Two-Sector Model}

To gain a better understanding of the different margins behind the cross-sectional-return premium, I work with a two-sector version of the model in the following. ${ }^{40}$ The advantage of the two-sector model is that I can directly relate movements in aggregate variables to movements in the sticky- and flexible-price sectors. This advantage comes at the cost of some of the real effects of nominal rigidities being lost due to a lower level of strategic interaction in price setting (see Carvalho (2006)).

Instead of simulating dividends and valuations at the firm level, I report returns for a claim on aggregate dividends at the sector level. Figures 4 and 5 plot the impulse response functions of several aggregate and sector-level variables to a one-standard-deviation monetary policy shock.

Contractionary monetary policy shocks lead to a drop in real output, $Y$. Inflation, $\pi$, decreases, as does the aggregate real-wage rate, $w$. Marginal utility, $\lambda$, however, goes up. Note that due to wage stickiness and habit formation, the drop in real wages is less than the drop in output, and the increase in marginal utility is an order of magnitude larger. As for sectoral variables, the relative price of sector $1, P 1$, increases compared to sector 2 , in line with the real reset price of sector $1, X 1$. The last two panels of Figure 4 show that monetary policy shocks lead to an increase in price dispersion, $D S$. The dispersion in prices, however, is substantially larger for the sticky-price sector.

Figure 5 documents that the drop in aggregate output leads to a decrease in output at the sector level. The decline in output for the sticky-price sector is larger compared to sector 2 due to the higher relative price. The decrease in sector output translates into lower sector dividends, $D$, stock prices, $S$, and returns, ret, with more negative reactions for sector 1 . Negative returns in times of high marginal utility is the key condition for a positive equity premium.

Figure 6 graphically analyzes the cross-sectional-return premium for sticky-price firms. I plot the average difference in dividends between the sectors with low and high frequencies of price adjustment, (Div sticky - Div $\left._{\text {flexible }}\right)$, and marginal utility, $\left(C_{t}-b C_{t-1}\right)^{-\gamma}$, as a function of aggregate output. I simulate the model 500 times, sort the difference in sector dividends and marginal utility based on the realization of aggregate output, and take the average across simulations. In times of low aggregate

\footnotetext{
${ }^{40}$ The appendix contains additional results and replicates the different calibration exercises of the previous section for the two-sector economy.
} 
output and high marginal utility, the sector with low frequency of price adjustment has lower dividends than the flexible price sector. Negative payoffs in times of high marginal utility are key for a positive cross-sectional-return premium for sticky price firms.

In the appendix, I show that the difference in log expected excess returns is approximately given by

$$
\begin{aligned}
\mathbb{E}_{t} r_{1, t+1}-\mathbb{E}_{t} r_{2, t+1}+\left[\frac{1}{2} \operatorname{var} r_{1, t+1}-\frac{1}{2} \operatorname{var} r_{2, t+1}\right] & \approx-\left(\varepsilon_{c k}-\varepsilon_{c}\right) \operatorname{cov}_{t}\left(m_{t, t+1},\left(p_{1, t+1}-p_{2, t+1}\right)\right) \\
- & \left(1-\varepsilon_{c k}\right) \operatorname{cov}_{t}\left(m_{t, t+1},\left(d s_{p, 1, t+1}-d s_{p, 2, t+1}\right)\right) .
\end{aligned}
$$

Cross-sectional-return premia are therefore determined by two covariance terms, the covariance of the $\log$ stochastic discount factor between period $\mathrm{t}$ and $\mathrm{t}+1, m_{t, t+1}$, and the relative price between the sticky- and flexible-price sectors, $\left(p_{1, t+1}-p_{2, t+1}\right)$, and the covariance with the relative price dispersion between the two sectors, $\left(d s_{p, 1, t+1}-d s_{p, 2, t+1}\right)$. Both covariance terms are positive. The model therefore implies a premium for firms with lower frequencies of price adjustment in three cases: when (i) the elasticity of substitution of consumption varieties across sectors, $\varepsilon_{c}$, is not much smaller than the elasticity within sector varieties, $\varepsilon_{c k}$; (ii) the elasticity across sector consumption goods, $\varepsilon_{c k}$, is larger than unity; or (iii) a combination of the two. ${ }^{41}$

Figures 4 and 5 also plot impulse response functions for different values of the elasticity of substitution of within-sector consumption composites to gain intuition for the effects of $\varepsilon_{c k}$ on the cross-sectional-return premium documented in Table $12 .{ }^{42}$ I show in the appendix that sector dividends are given by sector output times the sector profit margin, which can be expressed as the sector markup, $\mu_{k, t}$, minus one over the markup

$$
\begin{aligned}
D_{k, t} & =Y_{k, t}\left(1-\frac{1}{\mu_{k, t}}\right) \\
& =Y_{k, t}\left[1-\left(\frac{W_{t}}{P_{t}}\right)\left(\frac{1}{A_{t}}\right)\left(\frac{P_{k, t}}{P_{t}}\right)^{-1} D S_{p, k, t}\right] .
\end{aligned}
$$

The last expression documents that the markup margin can be further decomposed into a price and an inefficiency component.

\footnotetext{
${ }^{41}$ This expression approximately holds under joint log normality for claims to sector dividends that pay off only in period $t+1$. Numerically, I find that the first covariance term still results in a premium for sticky price firms as long as $\varepsilon_{c}$ is only slightly smaller than $\varepsilon_{c k}$.

${ }^{42} \varepsilon_{c k}$ low, medium, and high correspond to values of 8,12 , and 16 , respectively. The premium for sticky-price firms increases from $0.92 \%$ to $6.73 \%$ per year.
} 
Expressing this relation in percentage deviations from the steady state, ${ }^{43}$

$$
\check{D}_{k, t}=\check{Y}_{k, t}-\frac{Y_{k}-D_{k}}{D_{k}}\left[\left(\frac{\check{W}_{t}}{P_{t}}\right)-\check{A}_{t}-\left(\frac{\check{P_{k, t}}}{P_{t}}\right)+\check{D} \check{S}_{p, k, t}\right]
$$

Differences in sector dividends, $\check{D}_{1, t}-\check{D}_{2, t}$, are therefore determined by three margins: (i) a quantity margin, $\left(\check{Y}_{1, t}-\check{Y}_{2, t}\right)$; (ii) a relative price margin, $\left(\check{P}_{1, t}-\check{P}_{2, t}\right)$; and (iii) an inefficiency or price-dispersion margin, $-\left(\check{D} S_{p, 1, t}-\check{D S_{p, 2, t}}\right)$. After a contractionary monetary policy shock, a larger share of firms in the sticky-price sector cannot adjust their prices downward. The high relative price of sector 1 leads to a drop in demand compared to sector 2. In addition, the dispersion in prices is higher in the sticky-price sector. Therefore, firms in sector 1 gain along the price margin but lose along the quantity and inefficiency margins. We see in figures 4 and 5 that the disadvantage in the quantity margin and the advantage in the price margin decrease in the elasticity of substitution of within-sector consumption varieties. The negative effect of price dispersion on dividends increases in $\varepsilon_{c k}$. Taken together, the effects on the price and price-dispersion margins are quantitatively more important. Hence the difference in sector dividends decreases and the premium for sticky-price firms increases in $\varepsilon_{c k}$.

I show in the appendix that the elasticity of substitution of consumption varieties across sectors, $\varepsilon_{c}$, only affects the quantity margin $\left(\check{Y}_{1, t}-\check{Y}_{2, t}\right)$. Increasing $\varepsilon_{c}$ translates into larger negative difference in dividends between the sticky- and flexible-price sector and therefore increases the cross-sectional-return difference. This channel, however, is quantitatively small and of second order compared to the effects of $\varepsilon_{c k}{ }^{44}$

Habit formation in consumption implies that expected returns vary over time and are particularly high during recessions. To test this hypothesis, I define recessions and expansions as months in the bottom and top $25^{\text {th }}$ percentile of the GDP growth distribution, respectively, and measure the subsequently realized return spread between sticky- and flexible-price sectors in simulated data. The spread in annual returns in the two years after recessions is $4.1 \%$, whereas it is only $1.1 \%$ after expansions, indicating substantial variation in expected returns.

To test more systematically for time variation in expected returns, I run long-horizon

\footnotetext{
${ }^{43} \check{D}_{k, t} \equiv \frac{D_{k, t}-D_{k}}{D_{k}}$, where variables without time subscript indicate steady-state quantities.

${ }^{44}$ Figures 7 and 8 in the appendix show why technology shocks command only a small risk premium. Mean reversion in technology leads to a small reaction in aggregate output following the shock, translating into a small reaction in marginal utility of consumption and finally dividends, stock prices, and returns.
} 
regressions on simulated data. I regress the cumulative log excess returns of the L-H portfolio on log consumption surplus. Table 13 shows the classical patterns: high consumption compared to habit predicts low future excess returns. The regression coefficients increase in absolute value from -0.14 for one-quarter-ahead excess returns to -0.81 for the three-years horizon and then start to decline. The explanatory power peaks at a two-years horizon with consumption-surplus explaining $22 \%$ of the time-series variation.

The model therefore replicates my key empirical findings: a large cross-sectional premium for sticky-price firms that varies over the business cycle, and an equity premium in line with historical estimates.

\section{Conclusions}

Sticky prices have a long history in such different fields as macroeconomics, industrial organization, and marketing, and are key to explaining the business-cycle dynamics of real gross domestic output, consumption, and investment. I document that price rigidities are also a strong predictor of the cross section of stock returns. CAPM $\beta$ s are a function of many parameters and factors, and we have little knowledge about the fundamental drivers. The frequency of product price adjustment is a simple statistic at the firm level that can account for a considerable part of the determinants of firms' systematic risk. To the extent that firms equalize the costs and benefits of price adjustment, the higher cost of capital for sticky price firms reflects a holistic measure of the total costs of sticky prices. Therefore, price rigidities explain both business-cycle dynamics in aggregate quantities and cross-sectional variation in stock returns, and further bridge macroeconomics and finance.

To explain these effects in a consistent framework, I develop a multi-sector production-based asset-pricing model in which firms differ in their frequency of price adjustment. A sufficiently high elasticity of substitution between consumption varieties within sectors, $\varepsilon_{c k}$, is the central condition for obtaining a large cross-sectional-return premium for sticky-price firms. Three margins determine the cross-sectional-return difference: a quantity margin, a price margin, and an inefficiency margin associated with price dispersion. Whereas the first margin ceteris paribus lowers the return premium, the other two margins increase the difference in returns between sticky- and flexible-price 
firms with increasing $\varepsilon_{c k}$.

There are several potential extensions for future research. Labor is the only production factor in my current setup. Allowing for capital and investigating how investment at the firm level interacts with price stickiness would be interesting. ${ }^{45}$ New Keynesian models have strong predictions on how production is distributed across firms and sectors after aggregate shocks, with interesting implications for firm level investment. Furthermore, the current setup completely abstracts from capital-structure considerations. It assumes firms are fully equity-financed. The positive correlation between leverage and the frequency of price adjustment indicates that a departure from this assumption could be a fruitful avenue for future research. In addition, my current analysis neglects potential heterogeneity in wage stickiness across firms and industries. The importance of wage stickiness for the aggregate level of equity risk premia and the interaction with price stickiness underlines the importance of this question for future research. Ultimately, the cause of sticky prices and the determinants of differences in the frequency of price adjustment across firms within industry are the vital questions for future research. Access to large-scale micro datasets will hopefully allow us to make progress toward answering these important questions.

\footnotetext{
${ }^{45}$ To get interesting macro and asset-pricing implications, one has to depart from the convenient modeling tool of economy-wide rental markets for capital (see, e.g., Altig et al. (2011) and Lettau and Uhlig (2000)) and allow for firm-specific capital. This departure makes reset price at the firm level history dependent, and hence aggregation at the industry level less straightforward in a fully non-linear model. The appendix contains a sketch of optimal reset prices and capital stocks at the firm level in this setup.
} 


\section{References}

Ahern, K. (2012). Network centrality and the cross section of stock returns. Unpublished Manuscript, University of Southern California.

Altig, D., L. J. Christiano, M. Eichenbaum, and J. Linde (2011). Firm-specific capital, nominal rigidities and the business cycle. Review of Economic Dynamics 14 (2), 225247.

Anderson, E., N. Jaimovich, and D. Simester (2012). Price stickiness: Empirical evidence of the menu cost channel. Unpublished Manuscript, Northwestern University.

Andreasen, M. M., J. Fernández-Villaverde, and J. Rubio-Ramírez (2013). The pruned state-space system for non-linear DSGE models: Theory and empirical applications. Unpublished manuscript, University of Pennsylvania.

Bansal, R. and A. Yaron (2004). Risks for the long run: A potential resolution of asset pricing puzzles. The Journal of Finance 59(4), 1481-1509.

Banz, R. W. (1981). The relationship between return and market value of common stocks. Journal of Financial Economics 9(1), 3-18.

Barro, R. J. (2006). Rare disasters and asset markets in the twentieth century. The Quarterly Journal of Economics 121(3), 823-866.

Basu, S. and J. G. Fernald (1997). Returns to scale in U.S. production: Estimates and implications. The Journal of Political Economy 105(2), 249-283.

Berk, J. B., R. C. Green, and V. Naik (1999). Optimal investment, growth options, and security returns. The Journal of Finance 54 (5), 1553-1607.

Bernanke, B. S. and K. N. Kuttner (2005). What explains the stock market's reaction to Federal Reserve policy? The Journal of Finance 60(3), 1221-1257.

Bhattarai, S. and R. Schoenle (2012). Multiproduct firms and price-setting: Theory and evidence from U.S. producer prices. Unpublished manuscript, Brandeis University.

Bils, M. and P. J. Klenow (2004). Some Evidence on the importance of sticky prices. The Journal of Political Economy 112, 947-985.

Boldrin, M., L. J. Christiano, and J. D. Fisher (2001). Habit persistence, asset returns, and the business cycle. The American Economic Review, 149-166.

Burnside, C. (1996). Production function regressions, returns to scale, and externalities. Journal of Monetary Economics 37(2), 177-201.

Bustamante, M. and A. Donangelo (2012). Product market competition and industry returns. Unpublished manuscript, University of Texas at Austin.

Calvo, G. A. (1983). Staggered prices in a utility-maximizing framework. Journal of Monetary Economics 12(3), 383-398.

Campbell, J. Y. (1991). A variance decomposition for stock returns. The Economic Journal 101 (405), 157-179.

Campbell, J. Y. (1993). Intertemporal asset pricing without consumption data. The American Economic Review 83(3), 487-512.

Campbell, J. Y. (1996). Understanding risk and return. The Journal of Political Economy 104 (2), 298-345.

Campbell, J. Y. and J. H. Cochrane (1999). By force of habit: A consumption-based expla- 
nation of aggregate stock market behavior. The Journal of Political Economy 107(2), $205-251$.

Campbell, J. Y., C. Pflueger, and L. M. Viceira (2013). Monetary policy drivers of bond and equity risks. Unpublished manuscript, Harvard University.

Campbell, J. Y. and R. J. Shiller (1988a). The dividend-price ratio and expectations of future dividends and discount factors. Review of Financial Studies 1(3), 195-228.

Campbell, J. Y. and R. J. Shiller (1988b). Stock prices, earnings, and expected dividends. The Journal of Finance 43(3), 661-676.

Campbell, J. Y. and T. Vuolteenaho (2004). Bad beta, good beta. The American Economic Review 94(5), 1249-1275.

Carlson, M., A. Fisher, and R. Giammarino (2004). Corporate investment and asset price dynamics: Implications for the cross-section of returns. The Journal of Finance 59(6), 2577-2603.

Carvalho, C. (2006). Heterogeneity in price stickiness and the real effects of monetary shocks. The B.E. Journal of Macroeconomics 2(1), 1-56.

Chen, L. and X. Zhao (2009). Return decomposition. Review of Financial Studies 22(12), 5213-5249.

Christiano, L. J., M. Eichenbaum, and C. L. Evans (2005). Nominal rigidities and the dynamic effects of a shock to monetary policy. The Journal of Political Economy 113(1), $1-45$.

Cochrane, J. H. (2005). Asset pricing (revised edition).

Cochrane, J. H. (2008). The dog that did not bark: A defense of return predictability. Review of Financial Studies 21 (4), 1533-1575.

Coibion, O. and Y. Gorodnichenko (2011). Monetary policy, trend inflation, and the great moderation: An alternative interpretation. The American Economic Review 101(1), $341-70$.

Coibion, O. and Y. Gorodnichenko (2012). Why are target interest rate changes so persistent? American Economic Journal: Macroeconomics 4(4), 126-62.

Croce, M. (2012). Long-run productivity risk: A new hope for production-based asset pricing? Unpublished manuscript, University of North Carolina at Chapel Hill.

Daniel, K., M. Grinblatt, S. Titman, and R. Wermers (1997). Measuring mutual fund performance with characteristic-based benchmarks. The Journal of Finance 52(3), $1035-1058$.

Donangelo, A. (2013). Labor mobility and the cross-section of expected returns. The Journal of Finance (forthcoming).

Dotsey, M., R. G. King, and A. L. Wolman (1999). State-dependent pricing and the general equilibrium dynamics of money and output. The Quarterly Journal of Economics 114(2), 655-690.

Eichenbaum, M., N. Jaimovich, and S. T. Rebelo (2011). Reference prices, costs, and nominal rigidities. The American Economic Review 101(1), 234-62.

Eichenbaum, M. S., N. Jaimovich, S. Rebelo, and J. Smith (2013). How frequent are small price changes? American Economic Journal: Macroeconomics (forthcoming).

Epstein, L. G. and S. E. Zin (1989). Substitution, risk aversion, and the temporal behavior 
of consumption and asset returns: A theoretical framework. Econometrica 57(4), 937969.

Erceg, C. J., D. W. Henderson, and A. T. Levin (2000). Optimal monetary policy with staggered wage and price contracts. Journal of Monetary Economics 46 (2), 281-313.

Fama, E. F. (1976). Foundations of finance: Portfolio decisions and securities prices. Basic Books New York.

Fama, E. F. and K. R. French (1988). Dividend yields and expected stock returns. Journal of Financial Economics 22(1), 3-25.

Fama, E. F. and K. R. French (1992). The cross-section of expected stock returns. The Journal of Finance 47(2), 427-465.

Fama, E. F. and K. R. French (1993). Common risk factors in the returns on stocks and bonds. Journal of Financial Economics 33(1), 3-56.

Fama, E. F. and J. D. MacBeth (1973). Risk, return, and equilibrium: Empirical tests. The Journal of Political Economy, 607-636.

Favilukis, J. and X. Lin (2013). Wage rigidity: A solution to several asset pricing puzzles. Unpublished manuscript, London School of Economics.

Frazzini, A. and L. H. Pedersen (2013). Betting against beta. Journal of Financial Economics (forthcoming).

Gabaix, X. (2012). Variable rare disasters: An exactly solved framework for ten puzzles in macro-finance. The Quarterly Journal of Economics 127(2), 645-700.

Galí, J. (2009). Monetary Policy, inflation, and the Business Cycle: An introduction to the New Keynesian Framework. Princeton University Press.

Gârleanu, N., L. Kogan, and S. Panageas (2012). Displacement risk and asset returns. Journal of Financial Economics 105(3), 491-510.

Gilchrist, S., R. Schoenle, J. Sim, and E. Zakrajsek (2013). Inflation dynamics during the financial crisis. Unpublished manuscript, Brandeis University.

Goldberg, P. P. and R. Hellerstein (2011). How rigid are producer prices? Unpublished manuscript, Yale University.

Golosov, M. and R. E. Lucas Jr. (2007). Menu costs and Phillips curves. The Journal of Political Economy 115(2), pp. 171-199.

Gomes, J., L. Kogan, and M. Yogo (2009). Durability of output and expected stock retums. The Journal of Political Economy 117(5), 941-986.

Gomes, J., L. Kogan, and L. Zhang (2003). Equilibrium cross section of returns. The Journal of Political Economy 111(4), 693-732.

Gorodnichenko, Y. and S. Ng (2010). Estimation of DSGE models when the data are persistent. Journal of Monetary Economics 57(3), 325-340.

Gorodnichenko, Y. and M. Weber (2013). Are sticky prices costly? Evidence from the stock market. Unpublished manuscript, UC Berkeley.

Hansen, L. P. (1982). Large sample properties of generalized method of moments estimators. Econometrica 50(4), 1029-1054.

Hansen, L. P. and R. J. Hodrick (1980). Forward exchange rates as optimal predictors of future spot rates: An econometric analysis. The Journal of Political Economy 88(5), 829-853. 
Heer, B., T. Klarl, and A. Maussner (2012). Asset pricing implications of a New Keynesian model: A note. Unpublished manuscript, Augsburg University.

Hodrick, R. J. (1992). Dividend yields and expected stock returns: Alternative procedures for inference and measurement. Review of Financial studies 5(3), 357-386.

Hou, K. and D. T. Robinson (2006). Industry concentration and average stock returns. The Journal of Finance 61(4), 1927-1956.

Jermann, U. J. (1998). Asset pricing in production economies. Journal of Monetary Economics 41(2), 257-275.

Jones, C. S. and S. Tuzel (2012). Inventory investment and the cost of capital. Journal of Financial Economics.

Kaltenbrunner, G. and L. A. Lochstoer (2010). Long-run risk through consumption smoothing. Review of Financial Studies 23(8), 3190-3224.

Kaplan, G. and G. Menzio (2013). Deconstructing price dispersion. Unpublished manuscript, Princeton University.

Kashyap, A. K. (1995). Sticky prices: New evidence from retail catalogs. The Quarterly Journal of Economics 110(1), 245-274.

Kehoe, P. J. and V. Midrigan (2012). Prices are sticky after all. Unpublished manuscript, University of Minnesota.

Kim, J., S. Kim, E. Schaumburg, and C. A. Sims (2008). Calculating and using second-order accurate solutions of discrete time dynamic equilibrium models. Journal of Economic Dynamics and Control 32(11), 3397-3414.

Klenow, P. J. and O. Kryvtsov (2008). State-dependent or time-dependent pricing: does it matter for recent U.S. inflation? The Quarterly Journal of Economics 123(3), 863-904.

Klenow, P. J. and B. A. Malin (2010). Microeconomic evidence on price-setting. Handbook of Monetary Economics 3, 231-284.

Klenow, P. J. and J. L. Willis (2007). Sticky information and sticky prices. Journal of Monetary Economics 54, Supplement, 79-99.

Knotek II, E. S. (2008). Convenient prices, currency, and nominal rigidity: Theory with evidence from newspaper prices. Journal of Monetary Economics 55(7), 1303-1316.

Kogan, L. (2004). Asset prices and real investment. Journal of Financial Economics 73(3), 411-431.

Kogan, L. and D. Papanikolaou (2012). Firm characteristics and stock returns: The role of investment-specific shocks. Review of Financial Studies (forthcoming).

Koijen, R. S. and S. Van Nieuwerburgh (2011). Predictability of returns and cash flows. Annual Review of Financial Economics 3(1), 467-491.

Kuehn, L.-A., N. Petrosky-Nadeau, and L. Zhang (2012). An equilibrium asset pricing model with labor market search. Unpublished manuscript, Carnegie Mellon University.

Lettau, M. and S. C. Ludvigson (2001). Consumption, aggregate wealth, and expected stock returns. The Journal of Finance 56 (3), 815-849.

Lettau, M. and S. C. Ludvigson (2005). Expected returns and expected dividend growth. Journal of Financial Economics 76(3), 583-626.

Lettau, M. and H. Uhlig (2000). Can habit formation be reconciled with business cycle facts? Review of Economic Dynamics 3(1), 79-99. 
Lettau, M. and S. Van Nieuwerburgh (2008). Reconciling the return predictability evidence. Review of Financial Studies 21(4), 1607-1652.

Lewellen, J. and S. Nagel (2006). The conditional CAPM does not explain asset-pricing anomalies. Journal of Financial Economics 82(2), 289-314.

Li, E. X. N. and F. Palomino (2012). Nominal rigidities, asset returns and monetary policy. Unpublished manuscript, University of Michigan.

Lucca, D. and E. Moench (2013). The pre-FOMC announcement drift. The Journal of Finance (forthcoming).

Lustig, H. and A. Verdelhan (2012). Business cycle variation in the risk-return trade-off. Journal of Monetary Economics 59, Supplement.

Mehra, R. and E. C. Prescott (1985). The equity premium: A puzzle. Journal of Monetary Economics 15(2), 145-161.

Merton, R. C. (1973). An intertemporal capital asset pricing model. Econometrica 41(5), 867-887.

Midrigan, V. (2011). Menu costs, multiproduct firms, and aggregate fluctuations. Econometrica 79(4), 1139-1180.

Nakamura, E. and J. Steinsson (2008). Five facts about prices: A reevaluation of menu cost models. The Quarterly Journal of Economics 123(4), 1415-1464.

Nakamura, E. and J. Steinsson (2013). Price rigidity: Microeconomic evidence and macroeconomic implications. Annual Review of Economics (forthcoming).

Newey, W. K. and K. D. West (1987). A simple, positive semi-definite, heteroskedasticity and autocorrelation consistent covariance matrix. Econometrica 55(3), 703-708.

Novy-Marx, R. (2011). Operating leverage. Review of Finance 15(1), 103-134.

Orphanides, A. and J. C. Williams (2006). Monetary policy with imperfect knowledge. Journal of the European Economic Association 4 (2-3), 366-375.

Rietz, T. A. (1988). The equity risk premium: A solution. Journal of Monetary Economics 22(1), 117-131.

Rosenberg, B., K. Reid, and R. Lanstein (1985). Persuasive evidence of market inefficiency. The Journal of Portfolio Management 11(3), 9-16.

Rudebusch, G. D. (2002). Term structure evidence on interest rate smoothing and monetary policy inertia. Journal of Monetary Economics 49(6), 1161-1187.

Savor, P. and M. Wilson (2013). Asset pricing: A tale of two days. Journal of Financial Economics (forthcoming).

Shiller, R. (2000). Irrational Exuberance. Princeton, NJ: Princeton University Press.

Smets, F. and R. Wouters (2007). Shocks and frictions in U.S. business cycles: A Bayesian DSGE approach. The American Economic Review 97(3), 586-606.

Sveen, T. and L. Weinke (2007). Lumpy investment, sticky prices, and the monetary transmission mechanism. Journal of Monetary Economics 54, 23-36.

Taylor, J. B. (1999). Staggered price and wage setting in macroeconomics. Handbook of macroeconomics 1, 1009-1050.

Uhlig, H. (2007). Explaining asset prices with external habits and wage rigidities in a DSGE model. The American Economic Review 97(2), 239-243.

Van Binsbergen, J. H. (2012). Good-specific habit formation and the cross-section of 
expected returns. Unpublished Manuscript, Stanford University.

Vavra, J. (2013). Inflation dynamics and time-varying volatility: New evidence and an Ss interpretation. The Quarterly Journal of Economics (forthcoming).

Walsh, C. E. (2003). Speed limit policies: the output gap and optimal monetary policy. The American Economic Review 93(1), 265-278.

Weil, P. (1989). The equity premium puzzle and the risk-free rate puzzle. Journal of Monetary Economics 24(3), 401-421.

Woodford, M. (2003). Interest and Prices: Foundations of a Theory of Monetary Policy. Princeton University Press.

Yun, T. (1996). Nominal price rigidity, money supply endogeneity, and business cycles. Journal of Monetary Economics 37(2), 345-370.

Zbaracki, M. J., M. Ritson, D. Levy, S. Dutta, and M. Bergen (2004). Managerial and customer costs of price adjustment: Direct evidence from industrial markets. The Review of Economics and Statistics 86(2), 514-533.

Zhang, L. (2005). The value premium. The Journal of Finance 60(1), 67-103. 
Figure 1: Price of Wall Street Journal and Level of Industrial Production and Consumer Price Index

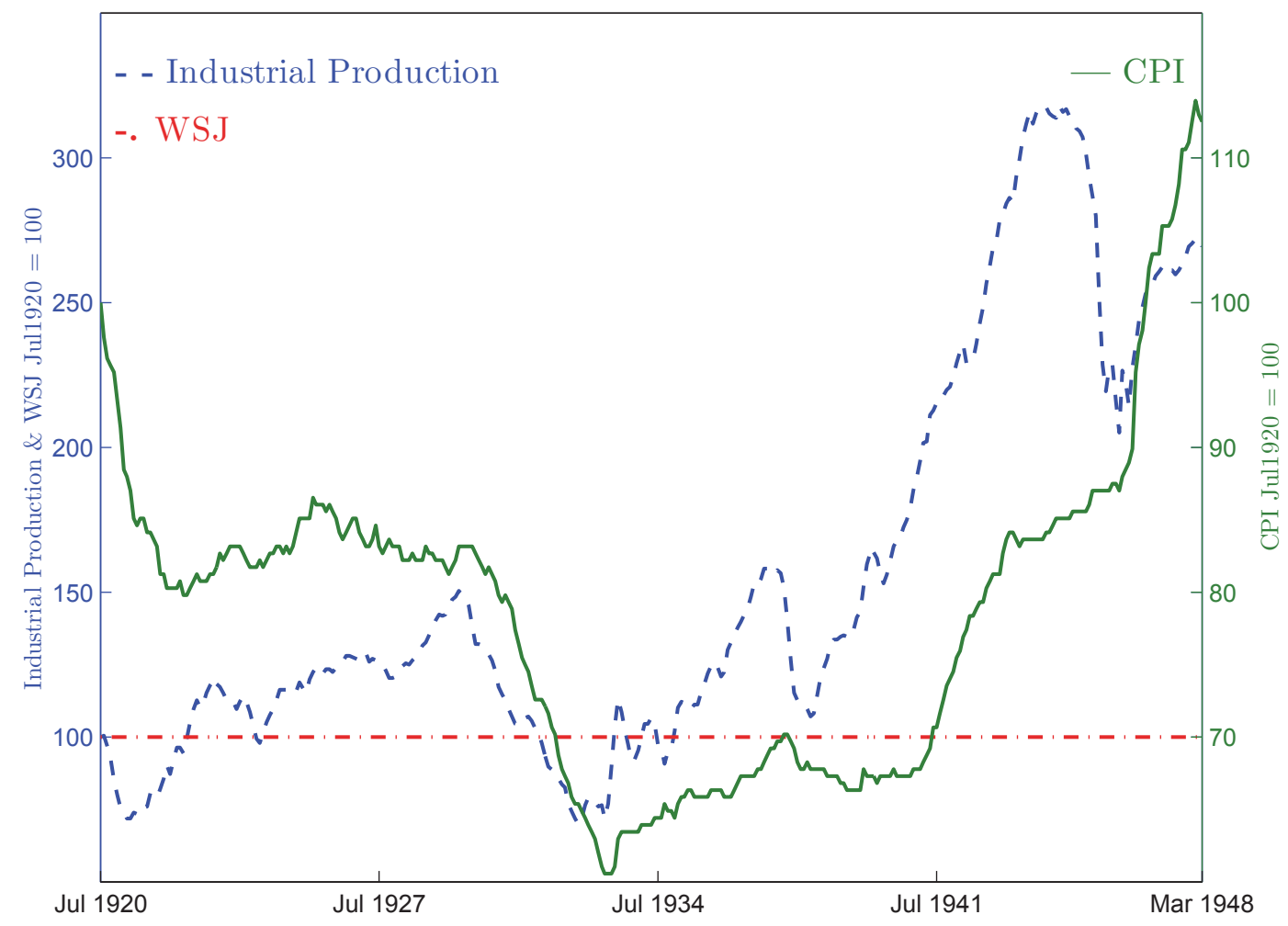

This figure plots the price of the Wall Street Journal (WSJ), Industrial Production (IP) and the Consumer Price Index (CPI) for a period from July 1920 to March 1948. The price of the WSJ, IP and the CPI are normalized to a value of 100 in July 1920. The price of the WSJ and IP are measured on the left y-axis whereas the CPI is measured on the right $y$-axis. 
Figure 2: Market Excess Return and Sticky minus Flexible Price Portfolio

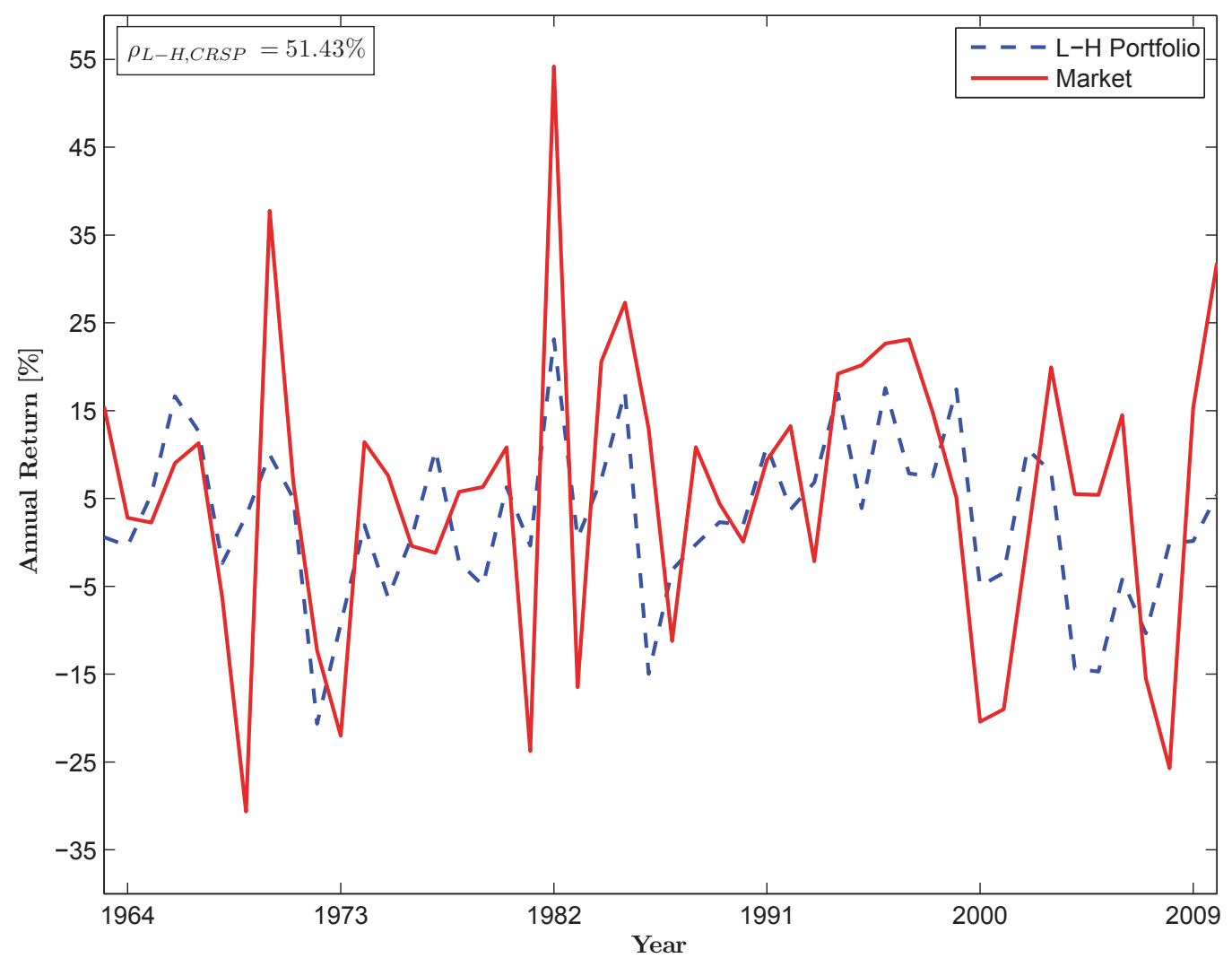

This figure plots the annual excess return of the CRSP value-weighted index (market) and the annual return of the zero-cost portfolio of going long the portfolio of stocks with low frequencies of price adjustment and shorting the portfolio of stocks with high frequencies of price adjustment, $L-H$. The sampling frequency is annual. The sample period is July 1963 to June 2011. 
Figure 3: Consumption Wealth Ratio (cay) and Following 5 Years Returns

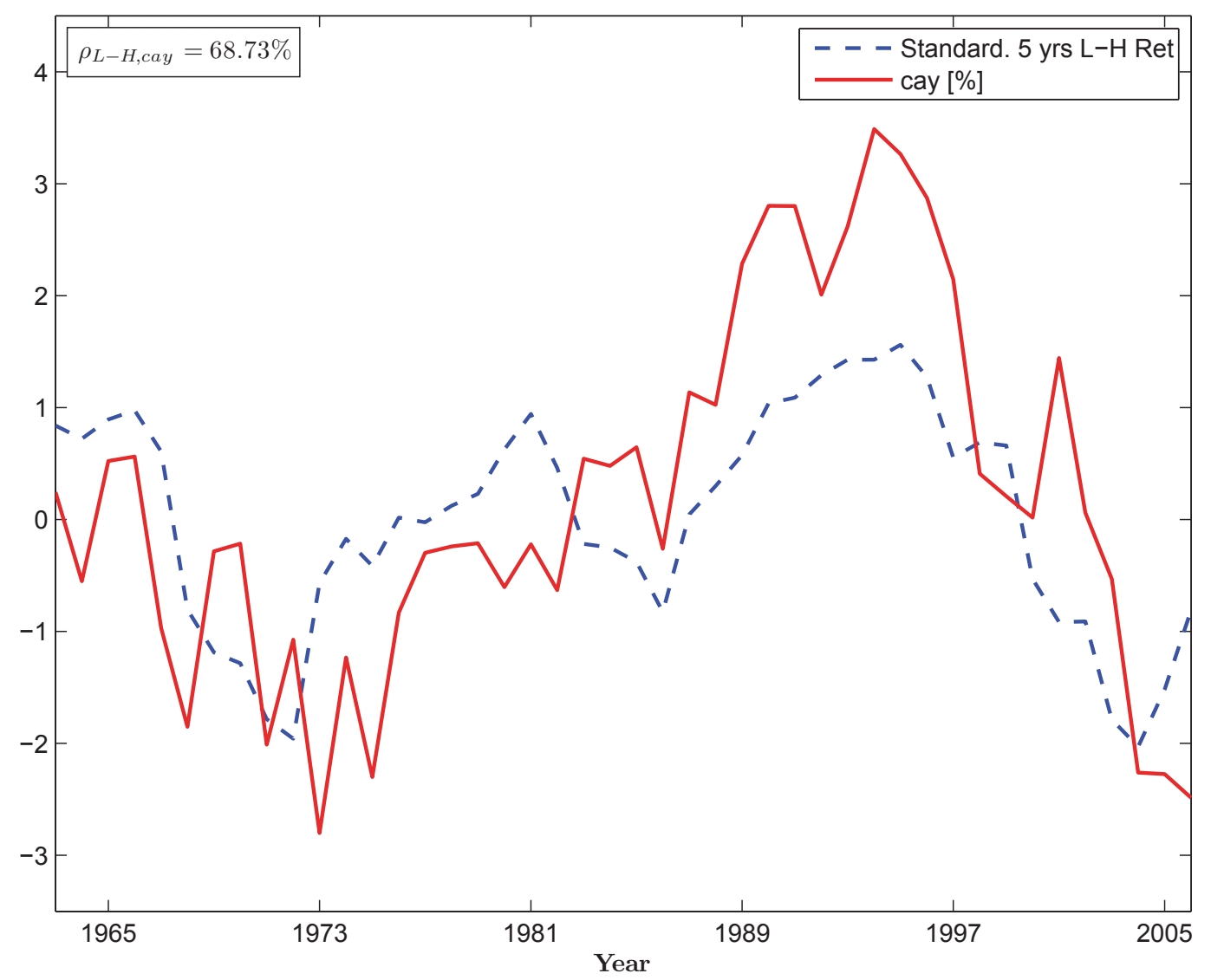

This figure plots the Lettau and Ludvigson (2001) proxy for the consumption wealth ration, cay, and the subsequently realized five years return of the zero-cost portfolio of going long the portfolio of stocks with low frequencies of price adjustment, and shorting the portfolio of stocks with high frequencies of price adjustment, $L$ - $H$. The sampling frequency is annual with cay observed at end of June of year $t$ and returns measured from July of year $t$ to June of year $t+5$. The sample period for cay is June 1963 to June 2006. 
Figure 4: Impulse Response Functions to Monetary Policy Shock (varying $\varepsilon_{c k}$ )
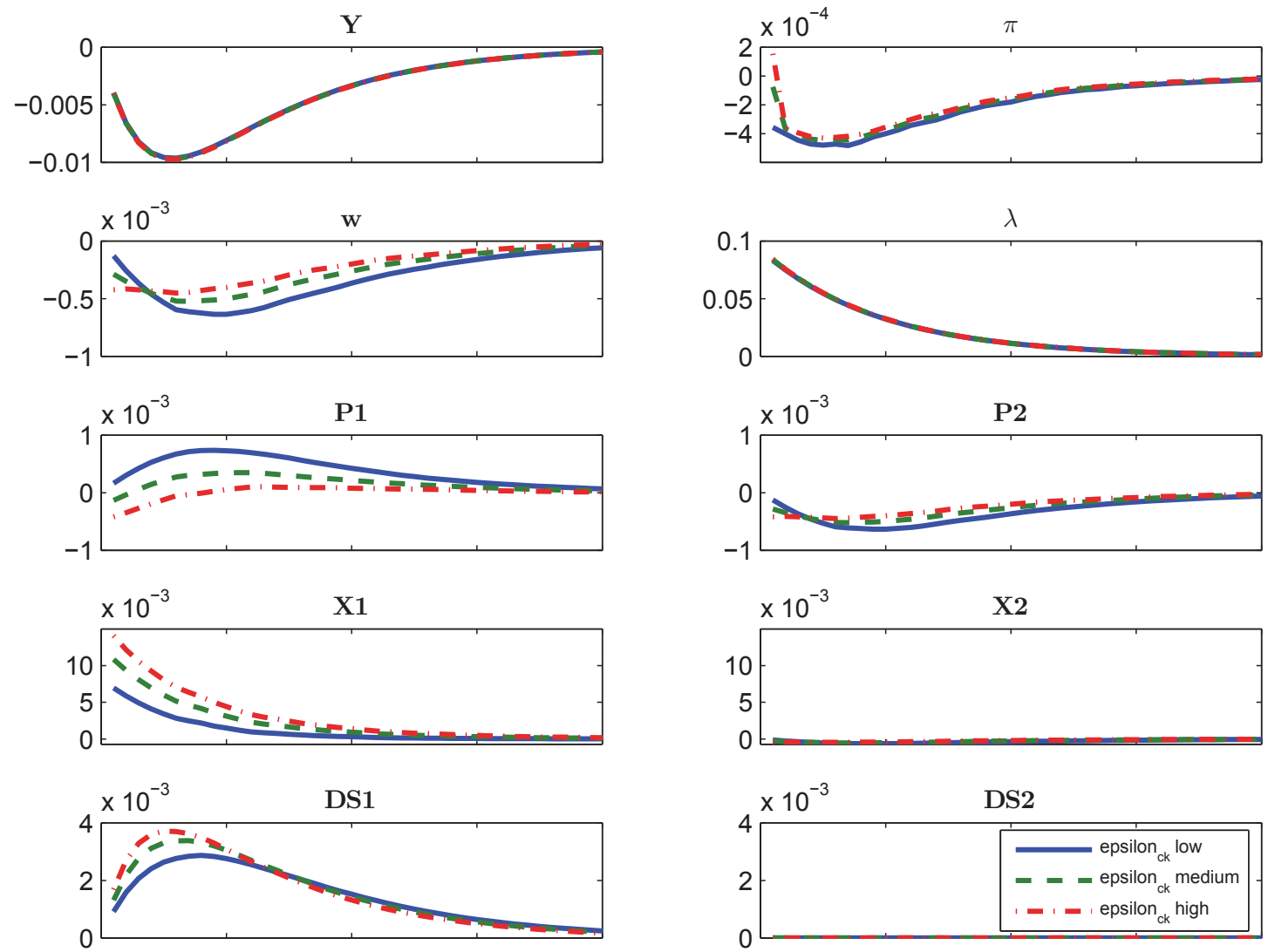

This figure plots the impulse response functions of several macroeconomic variables of the model of Section IV to a one standard deviation contractionary monetary policy shock for different values of the elasticity of substitution of within sector consumption varieties, $\varepsilon_{c k}$. $\varepsilon_{c k}$ low, medium and high correspond to values of 8 , 12 and 16 , respectively. $Y$ is output, $\pi$ inflation, $w$ aggregate real wage, $\lambda$ the marginal utility of consumption, $P 1$ and $P 2$ the relative prices of sectors one and two, X1 and X2 the optimal real reset prices, and DS1 and DS2 the price dispersion in the two sectors. 
Figure 5: Impulse Response Functions to Monetary Policy Shock (varying $\varepsilon_{c k}$ )

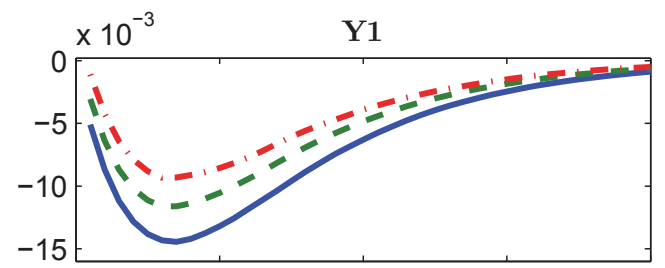

D1

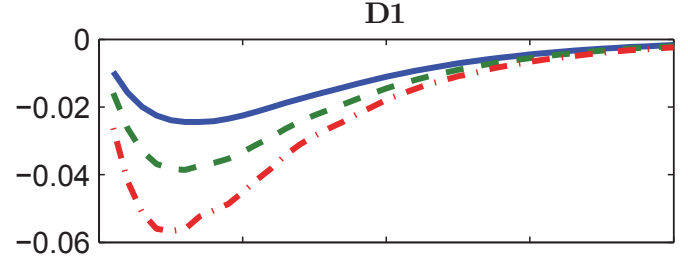

S1

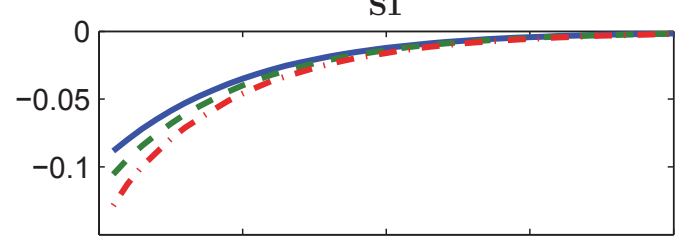

Ret1

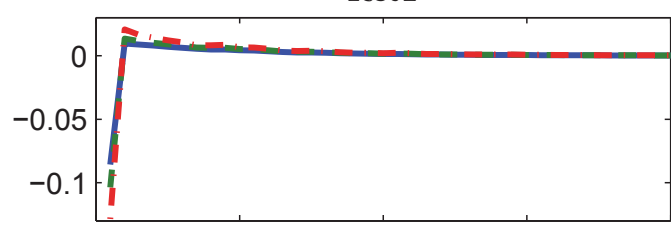

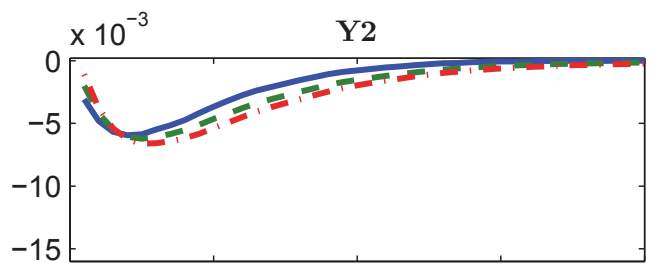
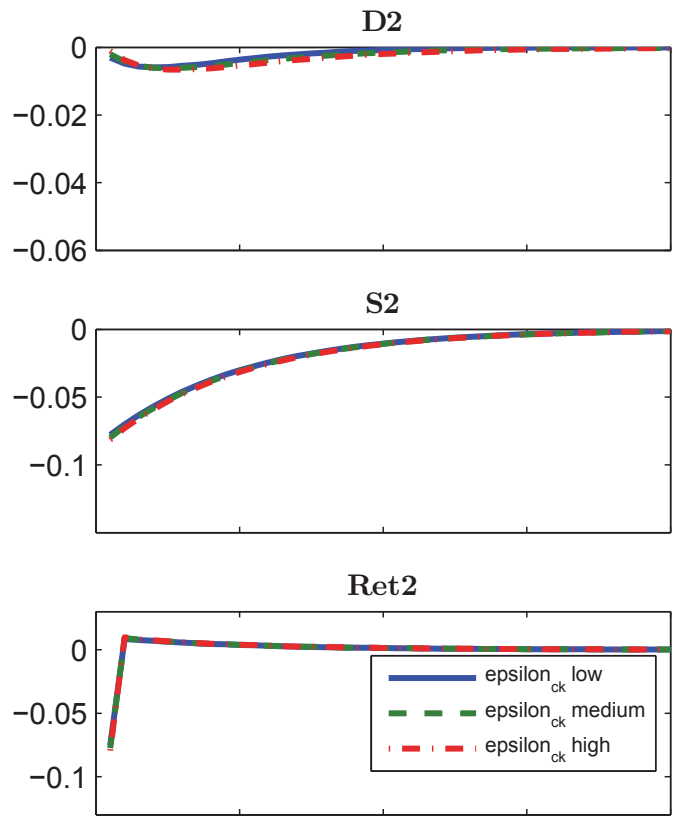

This figure plots the impulse response functions of several macroeconomic variables and asset returns of the model of Section IV to a one standard deviation contractionary monetary policy shock for different values of the elasticity of substitution of within sector consumption varieties, $\varepsilon_{c k}$. $\varepsilon_{c k}$ low, medium and high correspond to values of 8,12 and 16, respectively. Y1 and Y2 are the output of sectors one and two, D1 and D2 sector level dividends, S1 and S2 the prices of claims to aggregate sector dividends and Ret1 and Ret2 the returns of these claims. 
Figure 6: Difference in Sector Dividends and Marginal Utility

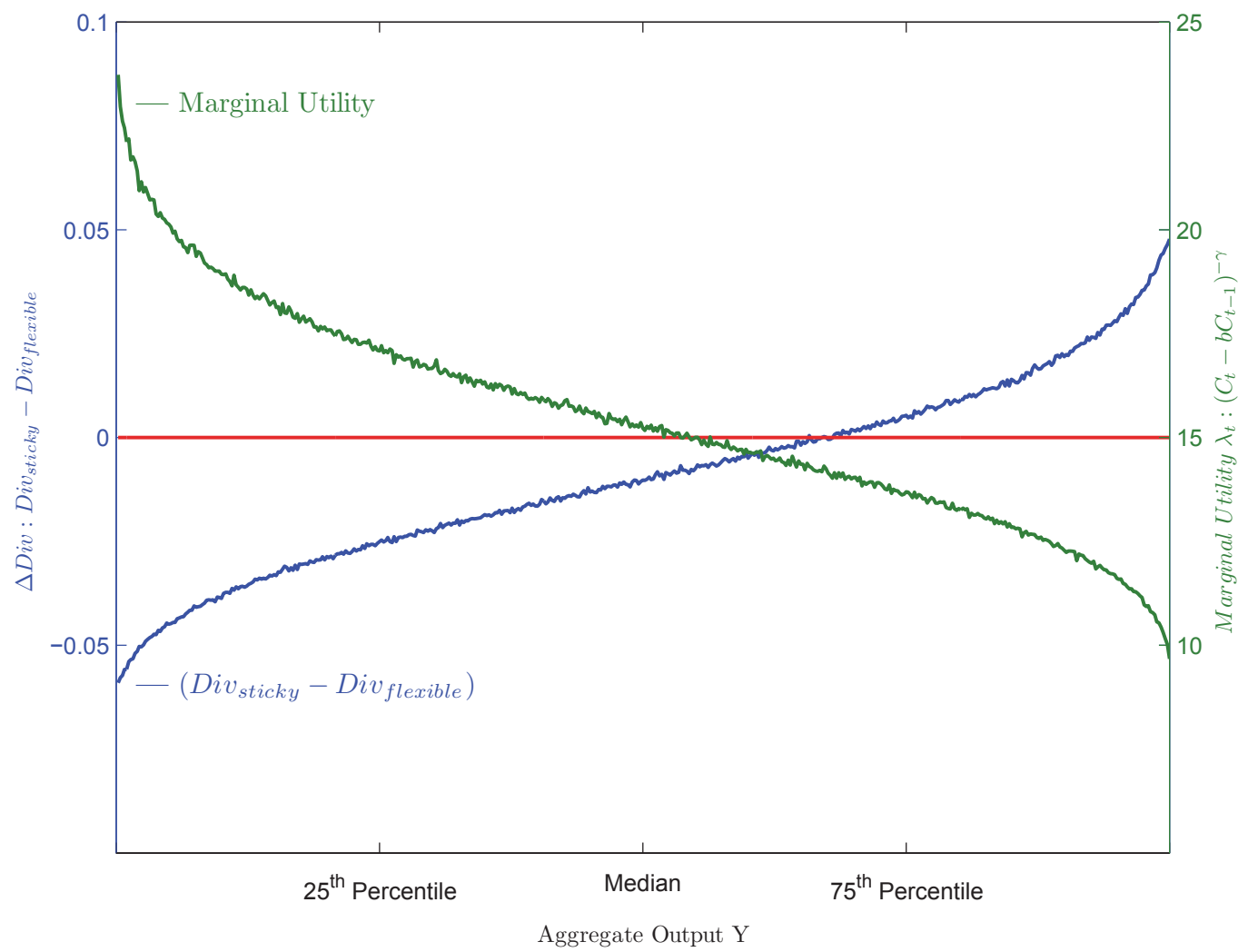

This figure plots the average difference in dividends of the sectors with low and high frequencies of price adjustment, (Div $v_{\text {sticky }}-$ Div $\left._{\text {flexible }}\right)$, and marginal utility, $\left(C_{t}-b C_{t-1}\right)^{-\gamma}$, as a function of aggregate output, $Y$. I simulate a two sector version of the model of Section IV 500 times, sort the difference in sector dividends and marginal utility based on the realization of aggregate output and take the average across simulations. The difference in dividends is measured on the left $y$-axis whereas marginal utility is measured on the right y-axis. 
Table 1: Frequency of Price Adjustment by Industry

This table reports average monthly frequencies of price adjustment, SA, at the industry and aggregate levels with standard deviations in parentheses. Panel A reports equally weighted frequencies, SAU, whereas Panel B weights frequencies with associated values of shipments, SAW. Frequencies of price adjustments are calculated at the firm level using the micro data underlying the Producer Price Index constructed by the Bureau of Labor Statistics. The sample period is July 1963 to June 2011.

\begin{tabular}{|c|c|c|c|c|c|c|c|}
\hline & $\begin{array}{c}\text { Agriculture } \\
\text { (1) }\end{array}$ & $\begin{array}{c}\text { Manufacturing } \\
\text { (2) }\end{array}$ & $\begin{array}{c}\text { Utilities } \\
(3)\end{array}$ & $\begin{array}{c}\text { Trade } \\
(4)\end{array}$ & $\begin{array}{c}\text { Finance } \\
(5)\end{array}$ & $\begin{array}{c}\text { Service } \\
\quad(6)\end{array}$ & $\begin{array}{c}\text { Total } \\
(7)\end{array}$ \\
\hline & \multicolumn{7}{|c|}{ Panel A. Measure SAU } \\
\hline Mean & $22.75 \%$ & $12.03 \%$ & $22.66 \%$ & $20.41 \%$ & $13.14 \%$ & $8.13 \%$ & $14.86 \%$ \\
\hline Std & $(17.49 \%)$ & $(11.35 \%)$ & $(12.79 \%)$ & $(13.74 \%)$ & $(11.31 \%)$ & $(9.19 \%)$ & $(13.00 \%)$ \\
\hline Max & $59.39 \%$ & $60.00 \%$ & $53.89 \%$ & $60.00 \%$ & $45.65 \%$ & $60.00 \%$ & $60.00 \%$ \\
\hline Min & $0.00 \%$ & $0.00 \%$ & $0.00 \%$ & $0.00 \%$ & $0.00 \%$ & $0.00 \%$ & $0.00 \%$ \\
\hline \multirow[t]{2}{*}{$\mathrm{N}$} & 16,754 & 139,235 & 42,425 & 19,124 & 40,380 & 15,618 & 273,536 \\
\hline & \multicolumn{7}{|c|}{ Panel B. Measure SAW } \\
\hline Mean & $25.03 \%$ & $13.12 \%$ & $23.03 \%$ & $20.75 \%$ & $13.65 \%$ & $9.20 \%$ & $15.79 \%$ \\
\hline Std & $(19.11 \%)$ & $(13.41 \%)$ & $(13.52 \%)$ & $(13.80 \%)$ & $(12.61 \%)$ & $(9.94 \%)$ & $(14.37 \%)$ \\
\hline Max & $59.39 \%$ & $60.00 \%$ & $55.83 \%$ & $60.00 \%$ & $46.84 \%$ & $60.00 \%$ & $60.00 \%$ \\
\hline Min & $0.00 \%$ & $0.00 \%$ & $0.00 \%$ & $0.00 \%$ & $0.00 \%$ & $0.00 \%$ & $0.00 \%$ \\
\hline $\mathrm{N}$ & 16,082 & 136,667 & 41,948 & 19,124 & 39,737 & 14,823 & 268,381 \\
\hline
\end{tabular}


Table 2: Summary Statistics and Correlations for Firm Characteristics and Return Predictors (Benchmark Sample)

This table reports time series averages of annual cross-sectional means and standard deviations for firm characteristics and return predictors used in the subsequent analysis in Panel A and contemporaneous correlations of these variables in Panel B. SAU measures the frequency of price adjustment. Equally weighted probabilities of price adjustments are calculated at the firm level using the micro data underlying the Producer Price Index constructed by the Bureau of Labor Statistics. Size is the natural logarithm of the market capitalization in thousands, BM is the book to market ratio, Beta is the regression coefficient on the market excess return in rolling times series regressions, Lev is financial leverage, CF measures cash flows, Turnover the fraction of shares traded to shares outstanding, spread is the mean bid - ask spread, PCM is the price to cost margin and HHI the Herfindahl - Hirschman index of sales at the Fama 8 French 48 industry level. Stock level data are from CRSP and financial statement data from Compustat. The sample period is July 1982 to June $200 \%$.

\begin{tabular}{|c|c|c|c|c|c|c|c|c|c|c|}
\hline & $\begin{array}{l}\text { SAU } \\
(1)\end{array}$ & $\begin{array}{l}\text { Size } \\
(2)\end{array}$ & $\begin{array}{c}\mathrm{BM} \\
(3)\end{array}$ & $\begin{array}{c}\text { Beta } \\
(4)\end{array}$ & $\begin{array}{l}\text { Lev } \\
(5)\end{array}$ & $\begin{array}{l}\mathrm{CF} \\
(6) \\
\end{array}$ & $\begin{array}{c}\text { Turnover } \\
(7)\end{array}$ & $\begin{array}{c}\text { Spread } \\
(8)\end{array}$ & $\begin{array}{c}\text { PCM } \\
(9) \\
\end{array}$ & $\begin{array}{l}\text { HHI } \\
(10)\end{array}$ \\
\hline & \multicolumn{10}{|c|}{ Panel A. Means and Standard Deviations } \\
\hline Mean & 0.14 & 14.76 & 0.63 & 1.09 & 0.40 & 0.09 & 10.43 & 1.31 & 0.37 & 0.13 \\
\hline Std & 0.13 & 1.25 & 0.37 & 0.42 & 0.23 & 0.06 & 8.34 & 0.64 & 0.18 & 0.32 \\
\hline \multirow[t]{2}{*}{$\mathrm{N}$} & 554 & 554 & 545 & 534 & 551 & 551 & 554 & 554 & 551 & 530 \\
\hline & \multicolumn{10}{|c|}{ Panel B. Contemporaneous Correlations } \\
\hline Size & 0.07 & & & & & & & & & \\
\hline BM & 0.26 & -0.14 & & & & & & & & \\
\hline Beta & -0.16 & -0.18 & -0.26 & & & & & & & \\
\hline Lev & 0.17 & 0.00 & 0.26 & -0.20 & & & & & & \\
\hline $\mathrm{CF}$ & -0.04 & 0.18 & -0.44 & 0.02 & -0.50 & & & & & \\
\hline Turnover & -0.03 & -0.18 & -0.10 & 0.46 & -0.17 & 0.05 & & & & \\
\hline Spread & 0.02 & -0.30 & 0.13 & 0.11 & 0.07 & -0.14 & -0.01 & & & \\
\hline PCM & -0.16 & 0.11 & -0.34 & 0.12 & -0.09 & 0.28 & 0.10 & -0.13 & & \\
\hline HHI & -0.06 & 0.04 & -0.06 & -0.04 & 0.01 & 0.09 & -0.06 & 0.01 & 0.01 & \\
\hline
\end{tabular}


Table 3: Mean Portfolio Returns (SAU)

This table reports time series averages of annual equally weighted portfolio raw returns in Panel $A$ and characteristic adjusted (DGTW) returns following Daniel et al. (1997) in Panel B for various sample periods with Newey and West (1987) standard errors in parentheses. Stocks are assigned to one of five baskets based on the frequency of price adjustment, SAU. Equally weighted probabilities of price adjustments are calculated at the firm level using the micro data underlying the Producer Price Index constructed by the Bureau of Labor Statistics. Panel C reports time series averages of annual returns for the CRSP value weighted index (CRSP VW), the CRSP equally weighted index (CRSP EW), the size (Size) and value (HML) factors of Fama and French (1993).

\begin{tabular}{llllllc}
\hline \hline & Sticky & S2 & S3 & S4 & Flexible & S1-S5 \\
& $(1)$ & $(2)$ & $(3)$ & $(4)$ & $(5)$ & $(6)$ \\
\hline \multirow{7}{c}{ Panel A. Annual Mean Returns } \\
\hline $07 / 1963-06 / 2011$ & $18.84 * * *$ & $18.42 * * *$ & $18.26 * * *$ & $16.97 * * *$ & $16.10 * * *$ & $2.74 *$ \\
& $(2.85)$ & $(2.02)$ & $(2.03)$ & $(2.19)$ & $(1.97)$ & $(1.46)$ \\
$07 / 1982-06 / 2007$ & $24.22 * * *$ & $21.98 * * *$ & $22.03 * * *$ & $21.00 * * *$ & $19.84 * * *$ & $4.38 * *$ \\
& $(3.08)$ & $(2.66)$ & $(2.35)$ & $(2.46)$ & $(2.47)$ & $(1.91)$ \\
$07 / 1982-06 / 1998$ & $28.77 * * *$ & $25.59 * * *$ & $25.20 * * *$ & $24.39 * * *$ & $22.05 * * *$ & $6.72 * * *$ \\
& $(3.53)$ & $(2.93)$ & $(3.23)$ & $(2.64)$ & $(2.89)$ & $(1.61)$
\end{tabular}

Panel B. Annual DGTW adjusted Returns

\begin{tabular}{ccccccc}
\hline $07 / 1963-06 / 2011$ & $4.42 * * *$ & $4.50 * * *$ & $4.14 * * *$ & $3.01 * * *$ & $2.34 * * *$ & $2.08 *$ \\
& $(1.32)$ & $(0.52)$ & $(0.40)$ & $(0.49)$ & $(0.81)$ & $(1.26)$ \\
$07 / 1982-06 / 2007$ & $6.81 * * *$ & $5.39 * * *$ & $4.36 * * *$ & $4.09 * * *$ & $3.11 * * *$ & $3.71 * *$ \\
& $(1.09)$ & $(0.27)$ & $(0.69)$ & $(0.63)$ & $(1.13)$ & $(1.63)$ \\
$07 / 1982-06 / 1998$ & $6.93 * * *$ & $4.97 * * *$ & $3.60 * * *$ & $3.03 * * *$ & $1.29 * * *$ & $5.64 * * *$ \\
& $(0.51)$ & $(0.39)$ & $(0.38)$ & $(0.36)$ & $(0.54)$ & $(0.91)$
\end{tabular}

Panel C. Annual Factor Returns

\begin{tabular}{lllll}
\hline & CRSP VW & CRSP EW & Size & HML \\
\hline $07 / 1963-06 / 2011$ & $11.28 * * *$ & $15.77 * * *$ & $3.37 * *$ & $5.10 * * *$ \\
& $(2.12)$ & $(2.08)$ & $(1.58)$ & $(1.04)$ \\
$07 / 1982-06 / 2007$ & $14.99 * * *$ & $16.75 * * *$ & 0.80 & $5.64 * * *$ \\
$07 / 1982-06 / 1998$ & $(2.81)$ & $(2.40)$ & $(1.67)$ & $(1.60)$ \\
& $19.52 * * *$ & $17.77 * * *$ & -1.50 & $4.63 * * *$ \\
& $(2.61)$ & $(3.58)$ & $(1.15)$ & $(1.13)$ \\
\hline \hline
\end{tabular}

Standard errors in parentheses

$* p<0.10, * * p<0.05, * * * p<0.01$ 
Table 4: Panel Regressions of Annual Stock Returns on Price Stickiness and Firm Characteristics (Benchmark Sample)

This table reports the results of regressing annual percentage returns on the frequency of price adjustment, SAU, firm characteristics, return predictors and year fixed effects, where indicated. Standard errors are clustered at the firm level and reported in parentheses. Equally weighted probabilities of price adjustments are calculated at the firm level using the micro data underlying the Producer Price Index constructed by the Bureau of Labor Statistics. Size is the natural logarithm of the market capitalization in thousands, BM is the book to market ratio, Beta is the regression coefficient on the market excess return in rolling times series regressions, Lev is financial leverage, CF measures cash flows, Turnover the fraction of shares traded to shares outstanding, Spread is the mean bid - ask spread, PCM is the price to cost margin and HHI the Herfindahl - Hirschman index of sales at the Fama \& French 48 industry level. Stock level data are from CRSP and financial statement data from Compustat. The sample period is July 1982 to June $200 \%$.

\begin{tabular}{|c|c|c|c|c|c|c|c|c|c|c|c|c|}
\hline & (1) & $(2)$ & (3) & $(4)$ & (5) & (6) & (7) & $(8)$ & (9) & $(10)$ & (11) & $(12)$ \\
\hline SAU & $\begin{array}{c}-10.04 * * * \\
(2.16)\end{array}$ & $\begin{array}{c}-10.97 * * * \\
(2.28)\end{array}$ & $\begin{array}{c}-8.04 * * * \\
(2.44)\end{array}$ & $\begin{array}{c}-12.94 * * * \\
(2.50)\end{array}$ & $\begin{array}{c}-8.54 * * * \\
(2.29)\end{array}$ & $\begin{array}{c}-10.99 * * * \\
(2.32)\end{array}$ & $\begin{array}{c}-10.98 * * * \\
(2.31)\end{array}$ & $\begin{array}{c}-9.83 * * * \\
(2.27)\end{array}$ & $\begin{array}{c}-10.16 * * * \\
(2.34)\end{array}$ & $\begin{array}{c}-9.52 * * * \\
(2.25)\end{array}$ & $\begin{array}{c}-10.79 * * * \\
(2.36)\end{array}$ & $\begin{array}{c}-7.07 * * * \\
(2.73)\end{array}$ \\
\hline Size & & & $\begin{array}{c}-4.38 * * * \\
(0.29)\end{array}$ & & & & & & & & & $\begin{array}{c}-4.97 * * * \\
(0.33)\end{array}$ \\
\hline $\mathrm{BM}$ & & & & $\begin{array}{l}3.22 * * * \\
(0.84)\end{array}$ & & & & & & & & $\begin{array}{l}3.21 * * * \\
(1.11)\end{array}$ \\
\hline Beta & & & & & $\begin{array}{l}4.12 * * * \\
(0.75)\end{array}$ & & & & & & & $\begin{array}{c}0.10 \\
(1.06)\end{array}$ \\
\hline Lev & & & & & & $\begin{array}{c}1.06 \\
(1.38)\end{array}$ & & & & & & $\begin{array}{l}4.35 * * \\
(1.84)\end{array}$ \\
\hline $\mathrm{CF}$ & & & & & & & $\begin{array}{c}-10.97 * * \\
(5.55)\end{array}$ & & & & & $\begin{array}{c}3.76 \\
(7.49)\end{array}$ \\
\hline Turnover & & & & & & & & $\begin{array}{l}52.39 * * * \\
(3.87)\end{array}$ & & & & $\begin{array}{l}37.00 * * * \\
(4.94)\end{array}$ \\
\hline Spread & & & & & & & & & $\begin{array}{c}-5.45 * * * \\
(0.54)\end{array}$ & & & $\begin{array}{c}-7.37 * * * \\
(0.57)\end{array}$ \\
\hline PCM & & & & & & & & & & $\begin{array}{l}5.61 * * * \\
(1.66)\end{array}$ & & $\begin{array}{l}7.84 * * * \\
(1.98)\end{array}$ \\
\hline HHI & & & & & & & & & & & $\begin{array}{c}0.23 \\
(0.70)\end{array}$ & $\begin{array}{c}1.79 * \\
(0.99)\end{array}$ \\
\hline Year Fixed Effects & $\mathrm{N}$ & $\mathrm{Y}$ & Y & $\mathrm{Y}$ & $\mathrm{Y}$ & $\mathrm{Y}$ & $\mathrm{Y}$ & $\mathrm{Y}$ & $\mathrm{Y}$ & $\mathrm{Y}$ & Y & $\mathrm{Y}$ \\
\hline Observations & 13,810 & 13,810 & 13,810 & 13,582 & 13,319 & 13,735 & 13,746 & 13,810 & 13,810 & 13,744 & 13,210 & 13,029 \\
\hline$R^{2}$ & $0.11 \%$ & $19.96 \%$ & $21.99 \%$ & $20.07 \%$ & $20.37 \%$ & $19.86 \%$ & $19.88 \%$ & $21.45 \%$ & $20.99 \%$ & $19.93 \%$ & $19.80 \%$ & $24.93 \%$ \\
\hline
\end{tabular}

Standard errors in parentheses

$* p<0.10, * * p<0.05, * * * p<0.0$ 
Table 5: Panel Regressions of Annual Stock Returns on Price Stickiness and Firm Characteristics (Benchmark Sample, Within Industry)

This table reports the results of regressing annual percentage returns on the frequency of price adjustment, SAU, firm characteristics, return predictors and year fixed effects, where indicated at the industry level. Standard errors are clustered at the firm level and reported in parentheses. Equally weighted probabilities of price adjustments are calculated at the firm level using the micro data underlying the Producer Price Index constructed by the Bureau of Labor Statistics. The sample period is July 1982 to June $200 \%$.

\begin{tabular}{lcccccccc}
\hline \hline & Baseline & Agriculture & Manufacturing & Utilities & Trade & Finance & Services & Dummies \\
$(1)$ & $(2)$ & $(3)$ & $(4)$ & $(5)$ & $(6)$ & $(7)$ & $(8)$ \\
\hline SAU & $-10.97 * * *$ & $-15.28 * *$ & $-7.34 *$ & $-9.13 * *$ & -9.35 & -2.32 & -11.38 & $-7.80 * * *$ \\
& $(2.28)$ & $(6.96)$ & $(4.17)$ & $(4.18)$ & $(8.92)$ & $(4.89)$ & $(19.63)$ & $(2.44)$ \\
& & & & & & & $\mathrm{Y}$ & $\mathrm{Y}$ \\
Year Fixed Effects & $\mathrm{Y}$ & $\mathrm{Y}$ & $\mathrm{Y}$ & $\mathrm{Y}$ & $\mathrm{Y}$ & $\mathrm{Y}$ & $\mathrm{Y}$ & $\mathrm{Y}$ \\
Industry Fixed Effects & $\mathrm{N}$ & $\mathrm{N}$ & $\mathrm{N}$ & $\mathrm{N}$ & $\mathrm{N}$ & $\mathrm{N}$ & $\mathrm{N}$ & 13,810 \\
Observations & 13,810 & 753 & 6,811 & 2,029 & 1,051 & 2,249 & 917 & $20.24 \%$ \\
$R^{2}$ & $19.96 \%$ & $27.15 \%$ & $20.50 \%$ & $25.51 \%$ & $38.89 \%$ & $44.58 \%$ & $21.07 \%$ \\
\hline \hline
\end{tabular}

Standard errors in parentheses

$* p<0.10, * * p<0.05, * * * p<0.01$ 


\section{Table 6: Mean of Double Sortings}

This table reports average annual returns for double sorted portfolios. I first assign stocks into tertiles based on various firm characteristics and then within each portfolio I assign stocks into tertiles based on the frequency of price adjustment, SAU. I report mean returns across characteristic sorts for the sticky, intermediate and flexible price portfolios as well as the difference between the two extreme portfolios. Newey and West (1987) standard errors are reported in parentheses. Equally weighted probabilities of price adjustments are calculated at the firm level using the micro data underlying the Producer Price Index constructed by the Bureau of Labor Statistics. Size is the natural logarithm of the market capitalization in thousands, BM is the book to market ratio, Beta is the regression coefficient on the market excess return in rolling times series regressions, Lev is financial leverage, CF measures cash flows, Turnover the fraction of shares traded to shares outstanding, Spread is the mean bid - ask spread, PCM is the price to cost margin and HHI the Herfindahl - Hirschman index of sales at the Fama 8 French 48 industry level. Stock level data are from CRSP and financial statement data from Compustat. The last two columns report results for conditional double sorts of Beta and BM on size. The sample period is July 1982 to June $200 \%$.

\begin{tabular}{|c|c|c|c|c|c|c|c|c|c|c|c|c|}
\hline & $\begin{array}{c}\text { Uncond } \\
(0)\end{array}$ & $\begin{array}{l}\text { Size } \\
(1)\end{array}$ & $\begin{array}{l}\mathrm{BM} \\
(2) \\
\end{array}$ & $\begin{array}{c}\text { Beta } \\
(3) \\
\end{array}$ & $\begin{array}{l}\text { Lev } \\
(4)\end{array}$ & $\begin{array}{c}\text { Spread } \\
(5)\end{array}$ & $\begin{array}{c}\text { PCM } \\
(6) \\
\end{array}$ & $\begin{array}{c}\text { Turnover } \\
(7)\end{array}$ & $\begin{array}{l}\mathrm{CF} \\
(8) \\
\end{array}$ & $\begin{array}{c}\mathrm{HHI} \\
(9) \\
\end{array}$ & $\begin{array}{c}\text { Beta } \\
\text { cond } \\
\text { Size } \\
(10)\end{array}$ & $\begin{array}{c}\text { BM } \\
\text { cond } \\
\text { Size } \\
(11)\end{array}$ \\
\hline Sticky & 23.32 & 21.56 & 22.08 & 21.89 & 22.07 & 21.83 & 22.20 & 21.51 & 21.92 & 21.75 & 19.83 & 22.22 \\
\hline $\mathrm{S} 2$ & 21.81 & 20.59 & 19.86 & 20.19 & 20.13 & 20.43 & 19.76 & 21.00 & 20.09 & 20.87 & 19.91 & 19.87 \\
\hline Flexible & 20.31 & 19.10 & 19.01 & 19.14 & 18.95 & 18.96 & 19.22 & 18.82 & 19.17 & 18.25 & 23.36 & 20.45 \\
\hline S1-S3 & $\begin{array}{l}3.02 * * * \\
(1.24)\end{array}$ & $\begin{array}{l}2.45 * * \\
(1.23)\end{array}$ & $\begin{array}{l}3.07 * * * \\
(0.94)\end{array}$ & $\begin{array}{l}2.74 * * \\
(1.24)\end{array}$ & $\begin{array}{l}3.12 * * * \\
(1.19)\end{array}$ & $\begin{array}{l}2.87 * * \\
(1.16)\end{array}$ & $\begin{array}{l}2.98 * * * \\
(0.91)\end{array}$ & $\begin{array}{l}2.69 * * \\
(1.20)\end{array}$ & $\begin{array}{l}2.75 * * * \\
(0.96)\end{array}$ & $\begin{array}{l}3.50 * * * \\
(1.26)\end{array}$ & $\begin{array}{c}-3.53 * \\
(1.81)\end{array}$ & $\begin{array}{c}1.78 \\
(1.51)\end{array}$ \\
\hline
\end{tabular}

Standard errors in parentheses

$* p<0.10, * * p<0.05, * * * p<0.01$ 


\section{Table 7: CAPM Regressions (Benchmark Sample)}

This table reports results for the unconditional CAPM in Panel A and the conditional CAPM in Panel B. Stocks are assigned to one of five baskets based on the frequency of price adjustment, $S A U$ and returns are equally weighted at the portfolio level. Equally weighted probabilities of price adjustments are calculated at the firm level using the micro data underlying the Producer Price Index constructed by the Bureau of Labor Statistics. $\alpha$ is the intercept and $\beta$ the slope of times series regressions of monthly portfolio excess returns on a constant and the excess return of the CRSP value weighted index. OLS and Fama and MacBeth (1973) standard errors are reported in parentheses and Newey and West (1987) standard errors in brackets. The conditional CAPM is monthly estimated on a rolling basis over the last twelve months following the methodology of Lewellen and Nagel (2006). The sample period is July 1982 to June $200 \%$.

\begin{tabular}{|c|c|c|c|c|c|c|}
\hline & $\begin{array}{c}\text { Sticky } \\
(1)\end{array}$ & $\begin{array}{l}\mathrm{S} 2 \\
(2) \\
\end{array}$ & $\begin{array}{l}\text { S3 } \\
(3)\end{array}$ & $\begin{array}{l}\text { S4 } \\
(4) \\
\end{array}$ & $\begin{array}{c}\text { Flexible } \\
(5)\end{array}$ & $\begin{array}{c}\text { S1-S5 } \\
(6)\end{array}$ \\
\hline & \multicolumn{6}{|c|}{ Panel A. Unconditional CAPM } \\
\hline$\alpha_{p}$ & 0.57 & 0.47 & 0.49 & 0.48 & 0.46 & 0.11 \\
\hline$S E_{O L S}$ & $(0.10) * * *$ & $(0.09) * * *$ & $(0.10) * * *$ & $(0.10) * * *$ & $(0.13) * * *$ & $(0.12)$ \\
\hline$S E_{N W}$ & {$[0.20] * * *$} & {$[0.13] * * *$} & {$[0.17] * * *$} & {$[0.15] * * *$} & {$[0.18] * *$} & {$[0.14]$} \\
\hline & 1.12 & 1.08 & 1.03 & 0.97 & 0.86 & 0.26 \\
\hline$S E_{O L S}$ & $(0.02) * * *$ & $(0.02) * * *$ & $(0.02) * * *$ & $(0.02) * * *$ & $(0.03) * * *$ & $(0.03) * * *$ \\
\hline \multirow[t]{2}{*}{$S E_{N W}$} & {$[0.05] * * *$} & {$[0.04] * * *$} & {$[0.06] * * *$} & {$[0.05] * * *$} & {$[0.07] * * *$} & {$[0.04] * * *$} \\
\hline & \multicolumn{6}{|c|}{ Panel B. Conditional CAPM } \\
\hline$\alpha_{p}$ & 0.41 & 0.35 & 0.38 & 0.37 & 0.40 & 0.00 \\
\hline$S E_{F M B}$ & $(0.05) * * *$ & $(0.03) * * *$ & $(0.04) * * *$ & $(0.04) * * *$ & $(0.04) * * *$ & $(0.05)$ \\
\hline$S E_{N W}$ & {$[0.19] * *$} & {$[0.12] * * *$} & {$[0.14] * * *$} & {$[0.13] * * *$} & {$[0.14] * * *$} & {$[0.14]$} \\
\hline$\beta_{p}$ & 1.29 & 1.21 & 1.15 & 1.08 & 0.91 & 0.37 \\
\hline$S E_{F M B}$ & $(0.02) * * *$ & $(0.01) * * *$ & $(0.01) * * *$ & $(0.01) * * *$ & $(0.02) * * *$ & $(0.02) * * *$ \\
\hline$S E_{N W}$ & {$[0.05] * * *$} & {$[0.04] * * *$} & {$[0.05] * * *$} & {$[0.04] * * *$} & {$[0.06] * * *$} & {$[0.05] * * *$} \\
\hline
\end{tabular}

Standard errors in parentheses

$* p<0.10, * * p<0.05, * * * p<0.01$ 


\section{Table 8: Cash Flow and Discount Rate Betas (Benchmark Sample)}

This table reports results for a beta decomposition into cash-flow $\beta, \beta_{C F}$, and discount-rate $\beta$, $\beta_{D R}$, following Campbell and Vuolteenaho (2004) as well as their sum. GMM (Hansen (1982)) standard errors conditional on the estimated news series are reported in parentheses. Stocks are assigned to one of five baskets based on the frequency of price adjustment, SAU and returns are equally weighted at the portfolio level. Equally weighted probabilities of price adjustments are calculated at the firm level using the micro data underlying the Producer Price Index constructed by the Bureau of Labor Statistics. The sample period is from July 1982 to June $200 \%$.

\begin{tabular}{lcccccc}
\hline \hline \hline & Sticky & $\mathrm{S} 2$ & $\mathrm{~S} 3$ & $\mathrm{~S} 4$ & Flexible & $\mathrm{S} 1-\mathrm{S} 5$ \\
& $(1)$ & $(2)$ & $(3)$ & $(4)$ & $(5)$ & $(6)$ \\
\hline$\beta_{p, C F}$ & $0.55 * * *$ & $0.54 * * *$ & $0.51 * * *$ & $0.48 * * *$ & $0.41 * * *$ & $0.14 * * *$ \\
& $(0.05)$ & $(0.05)$ & $(0.05)$ & $(0.04)$ & $(0.05)$ & $(0.03)$ \\
$\beta_{p, D R}$ & $0.60 * * *$ & $0.57 * * *$ & $0.54 * * *$ & $0.50 * * *$ & $0.44 * * *$ & $0.15 * * *$ \\
& $(0.067$ & $(0.06)$ & $(0.06)$ & $(0.06)$ & $(0.07)$ & $(0.03)$ \\
$\beta_{p}$ & 1.15 & 1.11 & 1.05 & 0.98 & 0.85 & 0.29 \\
\hline \hline
\end{tabular}

Standard errors in parentheses

$* p<0.10, * * p<0.05, * * * p<0.01$ 
Table 9: Return Sensitivities to Federal Funds Rate Surprises

This table reports results from regressing monthly percentage excess returns on a constant and the surprise component of the one-month change in the Federal Funds rate and the CAPM predicted response for five portfolios sorted on the frequency of price adjustment and the CRSP value weighted index (market). OLS standard errors are reported in parentheses and Newey and West (1987) standard errors in brackets. Equally weighted probabilities of price adjustments are calculated at the firm level using the micro data underlying the Producer Price Index constructed by the Bureau of Labor Statistics. The sample period is June 1989 to June $200 \%$.

\begin{tabular}{lccccccc}
\hline \hline \hline & Market & Sticky & $\mathrm{S} 2$ & $\mathrm{~S} 3$ & $\mathrm{~S} 4$ & Flexible & S1-S5 \\
& $(1)$ & $(2)$ & $(3)$ & $(4)$ & $(5)$ & $(6)$ & $(7)$ \\
\hline$\beta_{p, F F R}^{\text {actual }}$ & $-9.35 \%$ & $-11.42 \%$ & $-10.19 \%$ & $-9.35 \%$ & $-8.85 \%$ & $-5.01 \%$ & $-6.41 \%$ \\
& $(2.51) * * *$ & $(3.01) * * *$ & $(2.85) * * *$ & $(2.81) * * *$ & $(2.66) * * *$ & $(2.55) * *$ & $(1.55) * * *$ \\
& {$[2.66] * * *$} & {$[4.12] * * *$} & {$[3.46] * * *$} & {$[3.36] * * *$} & {$[3.37] * * *$} & {$[2.98] *$} & {$[2.26] * * *$} \\
$\beta_{p, F F R}^{\text {pred }}$ & & $-10.88 \%$ & $-10.65 \%$ & $-10.02 \%$ & $-9.38 \%$ & $-7.45 \%$ & $-3.41 \%$ \\
\hline \hline
\end{tabular}

Standard errors in parentheses

$* p<0.10, * * p<0.05, * * * p<0.01$ 


\section{Table 10: Long Horizon Predictability (Benchmark Sample)}

This table reports results for m-month forecasting regressions of log excess returns of the zero-cost portfolio of going long the portfolio of stocks with low frequencies of price adjustment, SAU, and shorting the portfolio of stocks with high frequencies of price adjustment on the log dividend-price ratio in Panel A, the break adjusted log dividend-price ratio in Panel B following the methodology of Lettau and Van Nieuwerburgh (2008) and the proxy for the consumption-wealth ratio of Lettau and Ludvigson (2001) in Panel C. For each regression the table reports OLS standard errors in parentheses, Newey and West (1987) standard errors in brackets, Hansen and Hodrick (1980) standard errors in curly brackets and Hodrick (1992) standard errors in angle brackets. Stocks are assigned to one of five baskets based on the frequency of price adjustment, SAU and returns are equally weighted at the portfolio level. Equally weighted probabilities of price adjustments are calculated at the firm level using the micro data underlying the Producer Price Index constructed by the Bureau of Labor Statistics. The sample period is July 1982 to June $200 \%$.

\begin{tabular}{lccccccc}
\hline \hline \hline Horizon m (Months) & 1 & 6 & \multicolumn{7}{c}{12} & 24 & 36 & 48 & 60 \\
\hline \multicolumn{7}{c}{ Panel A. Dividend Price Ratio } \\
\hline$b_{l h}^{(m)}$ & 0.00 & 0.01 & 0.01 & 0.01 & 0.02 & 0.03 & 0.05 \\
$S E_{O L S}$ & $(0.00)$ & $(0.01)$ & $(0.01)$ & $(0.02)$ & $(0.02)$ & $(0.02)$ & $(0.03) *$ \\
$S E_{N W}$ & {$[0.00]$} & {$[0.02]$} & {$[0.03]$} & {$[0.05]$} & {$[0.07]$} & {$[0.11]$} & {$[0.15]$} \\
$S E_{H H}$ & $\{0.00\}$ & $\{0.02\}$ & $\{0.03\}$ & $\{0.06\}$ & $\{0.08\}$ & $\{0.12\}$ & $\{0.15\}$ \\
$S E_{H}$ & $\langle 0.00\rangle$ & $\langle 0.02\rangle$ & $\langle 0.04\rangle$ & $\langle 0.09\rangle$ & $\langle 0.12\rangle$ & $\langle 0.15\rangle$ & $\langle 0.16\rangle$ \\
$R^{2}$ & $0.06 \%$ & $0.15 \%$ & $0.10 \%$ & $0.11 \%$ & $0.36 \%$ & $0.40 \%$ & $1.13 \%$
\end{tabular}

Panel B. Break Adjusted Dividend Price Ratio

\begin{tabular}{lccccccc}
\hline$b_{l h}^{(m)}$ & 0.00 & 0.02 & 0.04 & 0.10 & 0.21 & 0.29 & 0.39 \\
$S E_{O L S}$ & $(0.01)$ & $(0.01)$ & $(0.02) *$ & $(0.03) * * *$ & $(0.04) * * *$ & $(0.04) * * *$ & $(0.04) * * *$ \\
$S E_{N W}$ & {$[0.01]$} & {$[0.03]$} & {$[0.04]$} & {$[0.07]$} & {$[0.10] * *$} & {$[0.12] * *$} & {$[0.14] * * *$} \\
$S E_{H H}$ & $\{0.01\}$ & $\{0.03\}$ & $\{0.04\}$ & $\{0.08\}$ & $\{0.11\} *$ & $\{0.09\} * * *$ & $\{0.11\} * * *$ \\
$S E_{H}$ & $\langle 0.01\rangle$ & $\langle 0.04\rangle$ & $\langle 0.08\rangle$ & $\langle 0.14\rangle$ & $\langle 0.19\rangle$ & $\langle 0.21\rangle$ & $\langle 0.18\rangle * *$ \\
$R^{2}$ & $0.07 \%$ & $0.49 \%$ & $1.08 \%$ & $3.68 \%$ & $11.50 \%$ & $17.17 \%$ & $26.11 \%$
\end{tabular}

Panel C. Consumption Wealth Ratio

\begin{tabular}{lccccccc}
\hline$b_{l h}^{(m)}$ & 0.24 & 1.62 & 3.31 & 6.32 & 8.92 & 10.39 & 12.39 \\
$S E_{O L S}$ & $(0.08) * * *$ & $(0.18) * * *$ & $(0.22) * * *$ & $(0.34) * * *$ & $(0.45) * * *$ & $(0.64) * * *$ & $(0.69) * * *$ \\
$S E_{N W}$ & {$[0.07] * * *$} & {$[0.26] * * *$} & {$[0.47] * * *$} & {$[1.04] * * *$} & {$[1.59] * * *$} & {$[1.86] * * *$} & {$[1.38] * * *$} \\
$S E_{H H}$ & $\{0.06\} * * *$ & $\{0.29\} * * *$ & $\{0.53\} * * *$ & $\{1.17\} * * *$ & $\{1.61\} * * *$ & $\{0.76\} * * *$ & $\{0.16\} * * *$ \\
$S E_{H}$ & $\langle 0.07\rangle * * *$ & $\langle 0.42\rangle * * *$ & $\langle 0.85\rangle * * *$ & $\langle 1.60\rangle * * *$ & $\langle 2.50\rangle * * *$ & $\langle 3.76\rangle * * *$ & $\langle 3.96\rangle * * *$ \\
$R^{2}$ & $3.23 \%$ & $22.54 \%$ & $43.58 \%$ & $55.57 \%$ & $60.09 \%$ & $50.95 \%$ & $57.51 \%$ \\
\hline \hline
\end{tabular}

Standard errors in parentheses

$* p<0.10, * * p<0.05, * * * p<0.01$ 


\section{Table 11: Calibration}

This table shows in Panel A calibrated parameter values of the model of Section IV and the sectoral distribution of the frequency of price adjustment in Panel B.

\begin{tabular}{ccl}
\hline \hline & Panel A. Calibration Parameter \\
\hline Parameter & Value & Source \\
\hline$\beta$ & 0.99 & standard \\
$b$ & 0.76 & Altig et al. (2011) \\
$\gamma$ & 5 & Jermann (1998) \\
$\sigma$ & 2.5 & Carvalho (2006) \\
$\psi$ & 1 & Altig et al. (2011) \\
$\epsilon_{c}$ & 8 & Carvalho $(2006)$ \\
$\epsilon_{c k}$ & 12 & Carvalho $(2006)$ \\
$\theta_{w}$ & 0.825 & Heer et al. (2012) \\
$\epsilon_{w}$ & 8 & Altig et al. (2011) / Erceg et al. (2000) \\
$\phi_{\pi}$ & 1.24 & Rudebusch $(2002)$ \\
$\phi_{y}$ & $0.33 / 4$ & Rudebusch $(2002)$ \\
$\rho_{a}$ & 0.95 & Smets and Wouters (2007) \\
$\rho_{m}$ & 0.90 & Coibion and Gorodnichenko (2012) \\
& & \\
\hline \hline Sector $k$ & Panel B. Sectoral Distribution \\
\hline 1 & Share & Frequency of Price Adjustment \\
2 & 0.2 & 0.105 \\
3 & 0.2 & 0.164 \\
4 & 0.2 & 0.277 \\
5 & 0.2 & 0.638 \\
\hline \hline
\end{tabular}




\section{Table 12: Model Implied Stock Returns (5 Sectors)}

This table reports annualized mean excess returns for simulated data of the model of Section IV, the model implied equity risk premium (ERP), the Sharpe ratio (SR) as well as the sensitivity $\left(\beta_{S A U}\right)$ of annualized returns on the monthly frequency of price adjustment: $R_{j k, t}=\alpha+\beta_{S A U} \times\left(1-\theta_{k}\right)$. A five sector version of the model is calibrated using standard parameter values reported in Table 11 and the empirical distribution of the frequency of price adjustment of Nakamura and Steinsson (2008). The model is solved using a second order approximation as implemented in dynare employing the pruning package of Andreasen et al. (2013), calibrated at a quarterly frequency and simulated for 400 firms in each sector for 500 periods discarding the first 250 periods as burn in.

\begin{tabular}{|c|c|c|c|c|c|c|c|c|c|c|}
\hline & & Sticky & $\mathrm{S} 2$ & S3 & $\mathrm{S} 4$ & Flexible & S1-S5 & ERP & SR & $\beta_{S A U}$ \\
\hline (1) & Baseline & 7.91 & 6.84 & 6.56 & 5.96 & 5.51 & 2.39 & 6.56 & 0.39 & $-2.48 * * *$ \\
\hline$(2)$ & Equal Frequencies & 7.09 & 7.08 & 7.07 & 7.07 & 7.09 & 0.00 & 7.08 & 0.49 & \\
\hline$(3)$ & Flexible Prices & 7.49 & 7.49 & 7.49 & 7.49 & 7.49 & 0.00 & 7.49 & 0.50 & \\
\hline (4) & $\epsilon_{c}=\epsilon_{c k}=12$ & 8.45 & 6.88 & 6.54 & 5.93 & 5.48 & 2.97 & 6.65 & 0.39 & $-2.86 * * *$ \\
\hline (5) & $\epsilon_{c}=\epsilon_{c k}=8$ & 6.95 & 7.10 & 7.06 & 6.83 & 6.66 & 0.29 & 6.92 & 0.47 & $-0.55 * * *$ \\
\hline (6) & $\epsilon_{c k}=13$ & 8.70 & 6.81 & 6.41 & 5.68 & 5.15 & 3.55 & 6.55 & 0.36 & $-3.41 * * *$ \\
\hline (7) & $\epsilon_{c k}=11$ & 7.40 & 6.89 & 6.70 & 6.21 & 5.85 & 1.55 & 6.61 & 0.41 & $-1.76 * * *$ \\
\hline (8) & $\epsilon_{c}=10$ & 8.15 & 6.86 & 6.55 & 5.94 & 5.50 & 2.66 & 6.60 & 0.39 & $-2.66 * * *$ \\
\hline (9) & $\epsilon_{c}=6$ & 7.71 & 6.82 & 6.57 & 5.98 & 5.53 & 2.18 & 6.52 & 0.39 & $-2.33 * * *$ \\
\hline (10) & $\epsilon_{w}=6$ & 7.98 & 7.03 & 6.72 & 6.17 & 5.76 & 2.22 & 6.73 & 0.42 & $-2.31 * * *$ \\
\hline (11) & $\sigma=1$ & 8.51 & 7.07 & 6.70 & 6.20 & 5.82 & 2.69 & 6.86 & 0.43 & $-2.55 * * *$ \\
\hline (12) & Shock std $=0.009$ & 10.21 & 7.66 & 7.19 & 6.40 & 5.82 & 4.39 & 7.46 & 0.38 & $-4.05 * * *$ \\
\hline (13) & Baseline unpruned & 6.13 & 3.36 & 2.90 & 2.27 & 1.92 & 4.21 & 3.32 & 0.14 & $-3.60 * * *$ \\
\hline (14) & $\phi_{p i}=1.3$ & 5.98 & 5.88 & 5.76 & 5.41 & 5.16 & 0.82 & 5.64 & 0.38 & $-1.08 * * *$ \\
\hline$(15)$ & $\phi_{x}=0.5 / 4$ & 7.90 & 6.84 & 6.56 & 5.96 & 5.51 & 2.39 & 6.55 & 0.39 & $-2.47 * * *$ \\
\hline (16) & MP shocks only & 6.81 & 5.87 & 5.64 & 5.03 & 4.59 & 2.23 & 5.59 & 0.34 & $-2.37 * * *$ \\
\hline (17) & Technol shocks only & 1.08 & 0.97 & 0.89 & 0.83 & 0.81 & 0.27 & 0.92 & 0.47 & $-0.27 * * *$ \\
\hline (18) & $\phi_{x}=0.975$ & 9.19 & 7.85 & 7.46 & 6.80 & 6.32 & 2.87 & 7.52 & 0.43 & $-2.90 * * *$ \\
\hline (19) & Interest Rate Smoothing & 9.54 & 8.46 & 8.14 & 7.57 & 7.15 & 2.39 & 8.17 & 0.36 & $-2.45 * * *$ \\
\hline
\end{tabular}

$* p<0.10, * * p<0.05, * * * p<0.01$ 


\section{Table 13: Long-Horizon Predictability on Simulated Data}

This table reports results for q-quarters forecasting regressions of model implied log excess returns of the zero-cost portfolio of going long the claim to dividends of the sector with low frequencies of price adjustment and shorting the claim to dividends of the sector with high frequencies of price adjustment, $L-H$ on log consumption surplus of the model. For each regression the table reports OLS standard errors in parentheses, Newey and West (1987) standard errors in brackets, Hansen and Hodrick (1980) standard errors in curly brackets and Hodrick (1992) standard errors in angle brackets. The sample length is 250 quarters.

\begin{tabular}{|c|c|c|c|c|c|c|c|}
\hline Horizon q (Quarters) & 1 & 2 & 4 & 8 & 12 & 16 & 20 \\
\hline$b_{l h}^{(q)}$ & -0.14 & -0.26 & -0.48 & -0.79 & -0.81 & -0.77 & -0.68 \\
\hline$S E_{O L S}$ & $(0.03) * * *$ & $(0.04) * * *$ & $(0.06) * * *$ & $(0.10) * * *$ & $(0.13) * * *$ & $(0.17) * * *$ & $(0.20) * * *$ \\
\hline$S E_{N W}$ & {$[0.05] * * *$} & {$[0.07] * * *$} & {$[0.11] * * *$} & {$[0.20] * * *$} & {$[0.29] * * *$} & {$[0.40] *$} & {$[0.50]$} \\
\hline$S E_{H H}$ & $\{0.05\} * * *$ & $\{0.08\} * * *$ & $\{0.13\} * * *$ & $\{0.23\} * * *$ & $\{0.31\} * * *$ & $\{0.43\} *$ & $\{0.52\}$ \\
\hline$S E_{H}$ & $\langle 0.05\rangle * * *$ & $\langle 0.10\rangle * * *$ & $\langle 0.17\rangle * * *$ & $\langle 0.26\rangle * * *$ & $\langle 0.32\rangle * *$ & $\langle 0.36\rangle * *$ & $\langle 0.38\rangle *$ \\
\hline$R^{2}$ & $9.34 \%$ & $14.28 \%$ & $21.86 \%$ & $21.80 \%$ & $13.75 \%$ & $8.61 \%$ & $5.05 \%$ \\
\hline
\end{tabular}

Standard errors in parentheses

$* p<0.10, * * p<0.05, * * * p<0.01$ 